\title{
GEOLOGIA, PETROGRAFIA E QUÍMICA MINERAL DAS MICAS DOS GREISENS ESTANÍFEROS ASSOCIADOS AO PLUTON ÁGUA BOA, PITINGA (AM)
}

\author{
RÉGIS MUNHOZ KRÁS BORGES ${ }^{1,2}$, ROBERTO DALL'AGNOL ${ }^{2} \&$ HILTON TULIO COSTI ${ }^{2,3}$
}

\begin{abstract}
GEOLOGY, PETROGRAPHY AND MINERAL CHEMISTRY OF MICAS FROM TIN GREISEN ASSOCIATED WITH the ÁGUA BOA PLUTON, PITINGA (AM) Two main greisen types were characterized in the western border of Água Boa pluton, Pitinga Province: greisen 1, composed mainly of quartz, siderophyllite, topaz, and sphalerite, and greisen 2, composed essentially of quartz, phengite, and chlorite. In spite of the compositional and petrographic differences, both greisens were formed from the same parent rock, a hornblende-biotite alkali feldspar granite to syenogranite.

Chemical analyses carried out in electron microprobe showed the mica of greisen 1 is a siderophyllite wich displays moderated $\mathrm{Al}$ contents. The compositional range of these micas can be explained by $\mathrm{Fe}^{2+}$ substitution for $\mathrm{Al}^{3+}$ and $\mathrm{Li}$ in octahedral sites, with a coupled $\mathrm{Al}^{3+}$ substitution for $\mathrm{Si}^{4+}$ in tetrahedral sites. The mica of greisen 2 is a phengite, whose chemical variation is due to substitution of ${ }^{\mathrm{V}} \mathrm{Al}$ for $\mathrm{Fe}^{2+}$, coupled with $\mathrm{Si}^{4+}$ enrichment. The calculated $\mathrm{Li}$ contents in phengites are lower than those estimated in siderophyllite.

Petrographic data indicate that higher cassiterite contents occur in the chlorite-rich greisen 2 , which shows also high pyrite \pm galena contents. The greisen 1 is mineralized in sphalerite, besides cassiterite.
\end{abstract}

Keywords: Pitinga, Água Boa pluton, greisens, cassiterite, petrography, mineral chemistry

Resumo Na borda oeste do pluton Água Boa, na Província Estanífera de Pitinga, ocorrem duas tipologias de greisens estaníferos associados espacialmente à fácies granito rapakivi: greisen 1, constituído principalmente por quartzo, siderofilita, topázio e esfalerita, e greisen 2, formado essencialmente por quartzo, fengita e clorita. Apesar de suas diferenças composicionais e petrográficas, estes greisens se formaram a partir do mesmo protólito granítico, um hornblenda-biotita-álcali-feldspato-granito a sienogranito.

As análises químicas realizadas em microssonda eletrônica comprovam que a mica do greisen 1 é uma siderofilita com teores moderados em $\mathrm{Al}$, cuja variação composicional ocorre pela substituição de $\mathrm{Fe}^{2+}$ por $\mathrm{Al}^{3+} \mathrm{e} \mathrm{Li} \mathrm{nos} \mathrm{sítios} \mathrm{octaédricos,} \mathrm{com} \mathrm{geração} \mathrm{de}$ vacâncias, e concomitante substituição de $\mathrm{Al}^{3+}$ por $\mathrm{Si}^{4+}$ nos sítios tetraédricos. Por sua vez, as micas do greisen 2 apresentam composição de fengita, cujo principal mecanismo evolutivo é dado pela substituição de ${ }^{\mathrm{V}} \mathrm{Al}$ por $\mathrm{Fe}^{2+}$ nos sítios octaédricos, com enriquecimento acoplado de $\mathrm{Si}^{4+}$ às expensas de $\mathrm{Al}^{3+}$ nos sítios tetraédricos. Seus teores de $\mathrm{Li}$ calculado são ainda menores do que aqueles estimados para a siderofilita do greisen 1.

Nos greisens estudados, as maiores concentrações de cassiterita estão associadas ao greisen 2 rico em clorita, que também apresenta volumes consideráveis de pirita \pm galena. $O$ greisen 1 , por sua vez, também está mineralizado em esfalerita, além de cassiterita.

Palavras-chave: Pitinga, Granito Água Boa, greisens, cassiterita, petrografia, química mineral

INTRODUÇÃO A Província Estanífera de Pitinga está situada na porção sul do Escudo das Guianas, mais especificamente no contexto geológico-geocronológico da borda oeste da Província Amazônia Central. Esta província foi palco de extensos eventos vulcano-plutônicos de idade paleo a mesoproterozóica, que cobrem amplas áreas do cráton (Dall'Agnol et al. 1994).

Dall'Agnol et al. (1993) compararam alguns granitos estaníferos da Suíte Velho Guilherme, situada na porção oriental do Cráton Amazônico, com granitos mesozóicos da Província Peninsular da Tailândia, estes últimos representantes dos granitos estaníferos do SE asiático. Estes dois grupos de granitos diferem em vários aspectos (Dall'Agnol et al. 2000): os granitos do Cráton Amazônico apresentam idades paleo a mesoproterozóica, são do tipo-A, pertencem à série rapakivi, e colocam-se em um contexto tectônico distensivo, intracratônico, enquanto que os granitos estaníferos do SE asiático têm idade mesozóica, são do tipo-S, da série ilmenita, e se alojaram em um ambiente compressivo, colisional.

A mina Pitinga apresenta importantes jazimentos de cassiterita associados aos granitos Água Boa e Madeira (Daoud \& Antonietto Jr. 1985). Esta mina é uma das maiores produtoras mundiais de estanho, além de conter expressivas mineralizações de criolita e de metais raros, tais como Zr, Nb, Ta, Y, REE (Horbe et al. 1991). Três tipos de mineralizações primárias de cassiterita foram aí identificadas: associadas com a fácies albita-granito do pluton Madeira (1); relacionadas a greisens (2) e epissienitos sódicos (3) encontrados no pluton Água Boa (Costi et al. 2002).

Greisens são uma das principais fontes primárias de mineralizações estaníferas, não somente na Amazônia, como também em várias regiões produtoras do mundo. A exceção dos trabalhos realizados nos greisens Taboquinha, associados ao Complexo Granítico Santa Bárbara em Rondônia (Frank \& Pires 1991, Sparrenberger \& Bettencourt 2000), e do greisen de Potosi (Yokoi

1 - Curso de Pós-Graduação em Geologia e Geoquímica - CG/UFPA. Caixa Postal 1611. CEP 66075-900. Belém (PA). E-mail: munhoz@ufpa.br

2 - Grupo de Pesquisa Petrologia de Granitóides - CG/UFPA. Caixa Postal 1611. CEP 66075-900. Belém (PA). E-mail: robdal@ufpa.br

3 - Museu Paraense Emílio Goeldi - Av. Perimetral, 1901. CEP 66077-530. Belém (PA). E-mail: tulio@museu-goeldi.br 
et al. 1987), que foi estudado metalogeneticamente, mas sem a divulgação de análises mineralógicas e geoquímicas, praticamente não se dispõem de estudos sistemáticos em greisens na Amazônia. Na mina Pitinga, Daoud \& Antonietto Jr. (1985) descreveram ocorrências descontínuas de greisens filoneanos fortemente condicionados por zonas de fraturamentos na borda oeste do Granito Água Boa, que somente foram localizados devido às exposições geradas pela lavra de depósitos aluvionares.

Os greisens associados ao Granito Água Boa foram estudados petrograficamente e de caracterização preliminar de sua química mineral por Borges (1997), e estudos geoquímicos e de inclusões fluidas por Borges (2002). Os objetivos do presente trabalho são apresentar os aspectos geológicos e petrográficos destes greisens e aprofundar a discussão sobre a química mineral das micas presentes nos mesmos.

CONTEXTO GEOLÓGICO A mina Pitinga se localiza no norte do Amazonas, próximo à divisa com Roraima (Fig. 1A). As rochas mais antigas desta região são os granitóides cálcico-alcalinos da Suíte Água Branca (Fig. 1B), que estão em contacto com rochas vulcânicas do Grupo Iricoumé. Esta última é a unidade geológica de maior distribuição na área da mina, sendo intrudida por corpos graníticos do tipo-A (Horbe et al. 1991, Costi 2000). Esses granitos são seguidos na estratigrafia por sedimentos clásticos e rochas piroclásticas da Formação Urupi, sills toleiíticos e diques da Formação Quarenta Ilhas e por diabásios e basaltos alcalinos da Formação Seringa.

Um significativo número de dados geocronológicos foi obtido para as rochas vulcânicas e os granitos estaníferos da mina Pitinga nos últimos anos. Costi et al. (2000a) obtiveram pelo método Pb$\mathrm{Pb}$ em monocristal de zircão uma idade de $1888 \pm 3$ Ma para o Grupo Iricoumé. Tanto o Granito Europa (1829 $\pm 1 \mathrm{Ma}$, Costi et al. 2000a), quanto as diferentes fácies dos plutons Madeira (1824 $\pm 2 \mathrm{Ma}$ a $1818 \pm 2 \mathrm{Ma}$, Costi et al. 2000a) e Água Boa (1815 \pm 10 Ma a $1798 \pm 10$ Ma, Lenharo 1998) são mais jovens que esta seqüência vulcânica, o que sustenta a hipótese destes granitos não serem cogenéticos com as rochas extrusivas.

Os granitos Madeira e Água Boa (Fig. 1C) são os portadores das mineralizações de Sn explotadas na mina Pitinga, e foram estudados em detalhe por diversos autores (Daoud 1988, Horbe et al. 1991, Lenharo 1998, Costi 2000).

O Granito Água Boa é um batólito de aproximadamente $350 \mathrm{~km}^{2}$, alongado segundo NE-SW, composto por quatro fácies petrográficas (Daoud 1988, Lenharo 1998). Evidências de campo indicam que a fácies mais precoce é um hornblenda-biotita-granito denominado genericamente de granito rapakivi (Fig. 1C). Esta fácies é seguida sucessivamente por um biotita-granito porfirítico fino, um biotita-granito de granulação média a grossa, e finalmente por um topázio-granito porfirítico.

As mineralizações estaníferas primárias no pluton Água Boa estão associadas com greisens (Daoud 1988, Borges 1997) e epissienitos sódicos (Costi et al. 2002).

Aspectos geológicos dos greisens Em 1992, o Grupo Paranapanema deu início a um programa de sondagem rotativa na borda oeste do pluton Água Boa para avaliar as ocorrências de greisens filoneanos detectados em superfície quando da abertura de frente de lavra aluvionar.

Daoud (1988) sugeriu que os expressivos depósitos aluvionares de cassiterita vinculados ao Granito Água Boa foram frutos da erosão de uma cúpula granítica intensamente greisenizada, capaz de gerar reservas de grande porte. Neste modelo, os veios de greisens estudados no presente trabalho representariam as raízes desta cúpula erodida.

Nos furos estudados, os contactos dos greisens com os granitos geralmente são bruscos, segundo ângulos de $45^{\circ}$ e $60^{\circ}$ com o eixo dos testemunhos. Os greisens ocorrem interdigitados com granitos greisenizados, formando zonas bem definidas e bastante homogêneas, com espessura máxima de $5 \mathrm{~m}$, ou vênulas milimétricas a centimétricas encaixadas nos granitos (Borges 1997). Nestas zonas de interdigitação é muito comum também a ocorrência de vênulas de quartzo leitoso bem como de níveis centimétricos onde

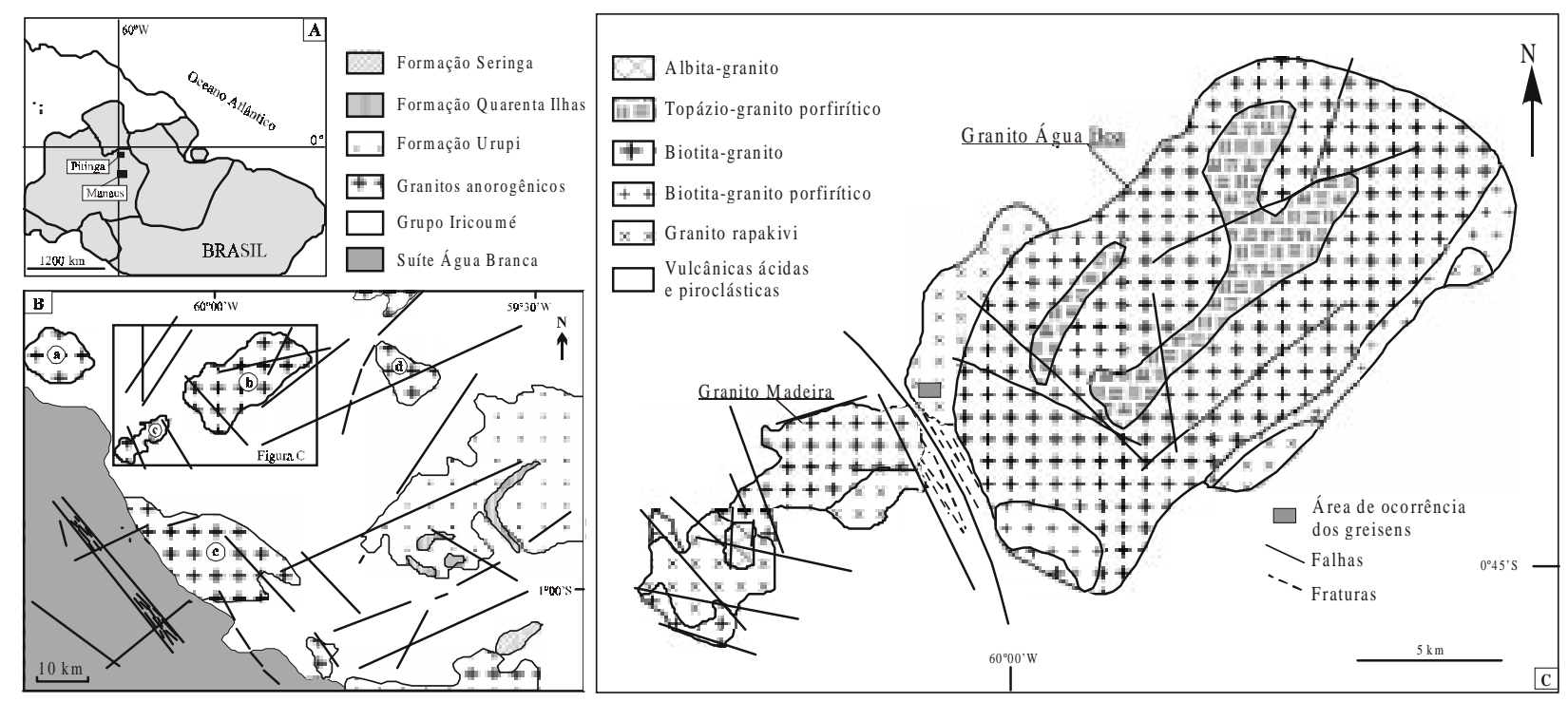

Figura 1 - A. Mapa de localização da região de Pitinga. B. Mapa geológico da região de Pitinga, com a distribuição dos granitos tipo-A: (a) Europa; (b) Água Boa; (c) Madeira; (d) Bom Futuro; (e) Simão. C. Mapa geológico dos granitos Madeira e Água Boa. Baseado em Costi et al. (2000a, modificado). 
se observa uma forte caolinização no granito.

FEIÇÕES MESOSCÓPICAS E MACROSCÓPICAS DOS GREISENS A malha de sondagem é constituída de 23 furos verticais, tendo sido recuperado um total de $820 \mathrm{~m}$ de testemunhos de rocha não intemperizada. Na etapa de campo todos estes furos foram estudados, inclusive o saprólito, visto que em vários níveis desta cobertura ocorrem greisens intemperizados. Posteriormente, foram selecionados oito furos para estudos de petrografia microscópica (Borges 1997).

No estudo petrográfico realizado, distinguiram-se duas tipologias de greisens com base em suas características mineralógicas e texturais (Borges 1997):

(a) - greisen 1 (Gs1): rocha de cor preta a cinza clara, com textura granular média, xenomórfica a hipidiomórfica, composta essencialmente por quartzo, topázio, siderofilita e esfalerita, acompanhados por quantidades variáveis de cassiterita, pirita, calcopirita, zircão, fluorita, siderita e anatásio;

(b) - greisen 2 (Gs2): rocha verde acinzentada escura a verde clara, com textura granular média xenomórfica. É constituída essencialmente por quartzo, fengita e clorita, com quantidades subordinadas de cassiterita, pirita, galena, esfalerita, zircão, rutilo, berilo e fluorita.

Um aspecto macroscópico característico dos greisens nos furos de sondagem é sua distribuição em zonas verticais bem definidas, onde a transição para as rochas graníticas encaixantes é marcada por granitos greisenizados, no caso do Gs1, ou por rochas muito hidrotermalizadas, correspondendo geralmente a epissienitos, no caso do Gs2.

Para a apresentar e discussão os dados petrográficos neste trabalho, foram selecionados o furo $\mathrm{F} 2$, representativo da zona de ocorrência do Gs1, e o furo F12, representativo da zona de ocorrência do Gs2. A distribuição dos greisens 1 e 2, e as relações com as encaixantes, é apresentada nos perfis das figuras 2 e 3 , respectivamente.

PETROGRAFIA MICROSCÓPICA DOSGREISENS Aspectos gerais A classificação destas rochas foi baseada em análises modais (Tabela 1) dos greisens (2000 pontos por seção delgada, em média). Os estudos microscópicos de detalhe, associados com os dados de análise modal, demonstraram a existência de variações mineralógicas internas em cada um dos greisens, definidas pela predominância de determinados minerais. As amostras dos greisens foram plotadas no diagrama de Kühne et al. (1972, modificado) (Fig. 4). O vértice representado pelas micas, no diagrama original, foi adaptado para os filossilicatos (siderofilita + fengita + clorita), em função das associações minerais observadas nas amostras estudadas. A distribuição dos greisens na figura 4 ressalta algumas diferenças mineralógicas importantes entre as duas tipologias. Assim, o Gs1 é nitidamente mais rico em quartzo e minerais de $\mathrm{F}$, enquanto que o Gs2 é relativamente pobre em quartzo $(<50 \%)$, mas mais rico em filossilicatos do que o Gs1. Por outro lado, a separação entre os dois subtipos mineralógicos de greisen é mais marcante para o Gs1, enquanto que os dois subtipos do Gs2 se superpõem no diagrama, em parte porque fengita e clorita estão colocados em um mesmo vértice.

Os dados modais (Tabela 1) ressaltam algumas diferenças composicionais marcantes entre os dois greisens. Enquanto que no Gs2 os filossilicatos essenciais são fengita e clorita, no Gs1 o filossilicato da associação é a siderofilita. Neste último, a fengita e, principalmente, a clorita, ocorrem como minerais de alteração tar- dia da siderofilita. No Gs1 ocorrem duas fases portadoras de F, sendo o topázio a predominante, seguida pela fluorita; no Gs2, ocorre apenas fluorita, rara e sempre em pequenas quantidades. A mineralogia de sulfetos também é diferenciada, sendo o Gs1 rico em esfalerita, enquanto que no Gs2 predominam pirita, calcopirita e galena, com as maiores proporções modais na zona rica em clorita. Por outro lado, os maiores conteúdos de cassiterita foram registrados no Gs2.

Feições microscópicas dos greisens GREISEN 1 (GS1) O Gs1 apresenta textura granular média a fina, xenomórfica a hipidiomórfica, sendo notável o desenvolvimento de uma zonação mineralógica interna na zona greisenizada. Nas zonas de contacto com os granitos greisenizados, esses greisens são relativamente enriquecidos em siderofilita (zona rica em siderofilita, ZS), e nas porções mais centrais do perfil em topázio (zona rica em topázio, ZT) (ver Fig. 2 e Tabela 1).

Na Figura 4, as amostras da ZT distribuem-se principalmente ao longo do campo III, com algumas no campo II, e são classificadas como mica-topázio-quartzo-greisen a topázio-quartzo-greisen, respectivamente. As amostras da ZS ocupam principalmente o campo IV, com algumas no campo V, correspondendo a topázio-micaquartzo-greisen com variação para mica-quartzo-greisen.

Nestes greisens, o quartzo desenvolve cristais anédricos, comumente fraturados, com 0,2 a 4,5 mm. Nos contactos com os granitos greisenizados, observam-se texturas de dissolução em minerais como albita, feldspato alcalino e micas, com posterior substituição por quartzo, resultando em mosaicos de grãos.

O topázio ocorre principalmente em massas ou agregados, na forma de prismas curtos, fraturados, com dimensão média em torno de 0,2 mm. Os dados modais (Tab. 1) e as evidências petrográficas indicam que nas amostras onde o topázio é mais abundante há uma sensível diminuição no conteúdo de siderofilita.

A siderofilita constitui agregados de lamelas subédricas a euédricas, com dimensões entre 0,3 e 1,2 mm, e com pleocroísmo entre marrom claro e creme. Apresenta-se parcialmente substituída por clorita verde oliva, principalmente próximo a vênulas tardias. De modo geral, a clorita é escassa (Tab. 1).

A cassiterita ocorre disseminada e sob duas formas: (a) em cristais anédricos a subédricos, marrom avermelhados a incolores ( $>1 \mathrm{~mm})$, associados a anatásio, siderofilita, esfalerita e quartzo, e (b) em grãos anédricos, incolores a vermelho pálido $(<1 \mathrm{~mm})$, associados ou inclusos em topázio, quartzo, esfalerita, calcopirita e siderofilita parcialmente cloritizada. Ambos tipos apresentam uma zonação composicional irregular, do tipo "em manchas" (Costi et al. 2000b), e um discreto pleocroísmo.

A esfalerita ocorre em grãos avermelhados a alaranjados, com dimensões entre 0,2 e $2 \mathrm{~mm}$, subédricos a euédricos. É uma fase mineral importante nesse greisen, atingindo proporções modais expressivas em várias amostras. A pirita ocorre em agregados de grãos euédricos a subédricos, seguidamente associada à esfalerita e/ou cassiterita. O anatásio normalmente ocorre em cristais quadráticos ou prismáticos escuros com tom azulado, de relevo muito alto, e dimensão média de $0,3 \mathrm{~mm}$. A fluorita ocorre como inclusão em filossilicatos, ou como grãos intersticiais maiores, com dimensão média de $0,5 \mathrm{~mm}$. Os cristais são incolores ou roxos, seguidamente associados com anatásio. $\mathrm{O}$ zircão normalmente ocorre em prismas curtos ou alongados euédricos, por vezes zonados e, em média, com 0,25 mm. Os carbonatos formam grãos intersticiais, com dimensão média de $0,3 \mathrm{~mm}$, associados preferencialmente à pirita e/ou esfalerita. 


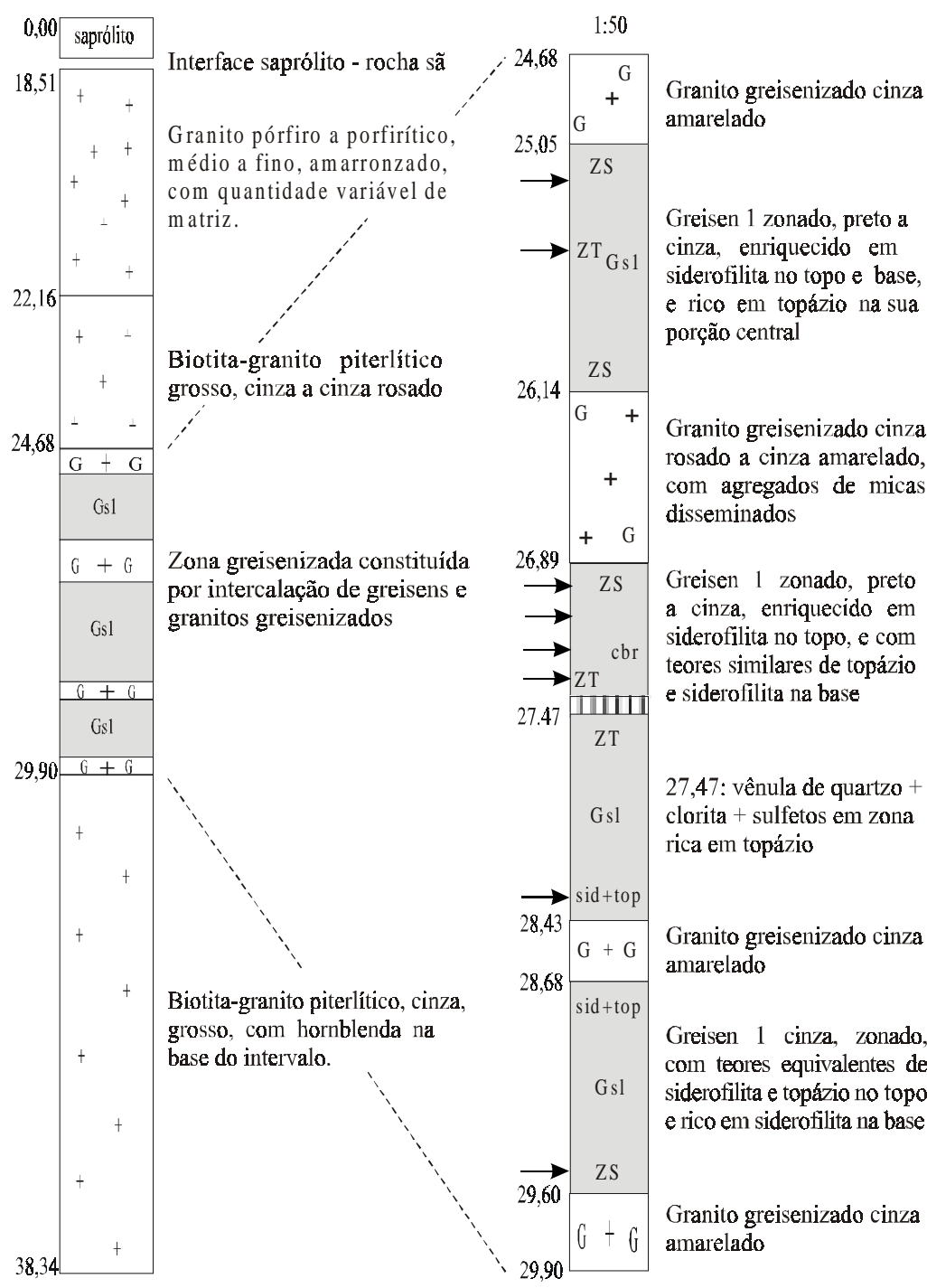

Figura 2 - Perfil esquemático do furo F2, representativo da zona de ocorrência do greisen 1. As setas indicam a localização de amostras com análise modal (ver Tab. 1). ZT: zona rica em topázio; ZS: zona rica em siderofilita; G: granito greisenizado; sid + top: zona com proporções modais semelhantes de siderofilita e topázio; clor clorita.

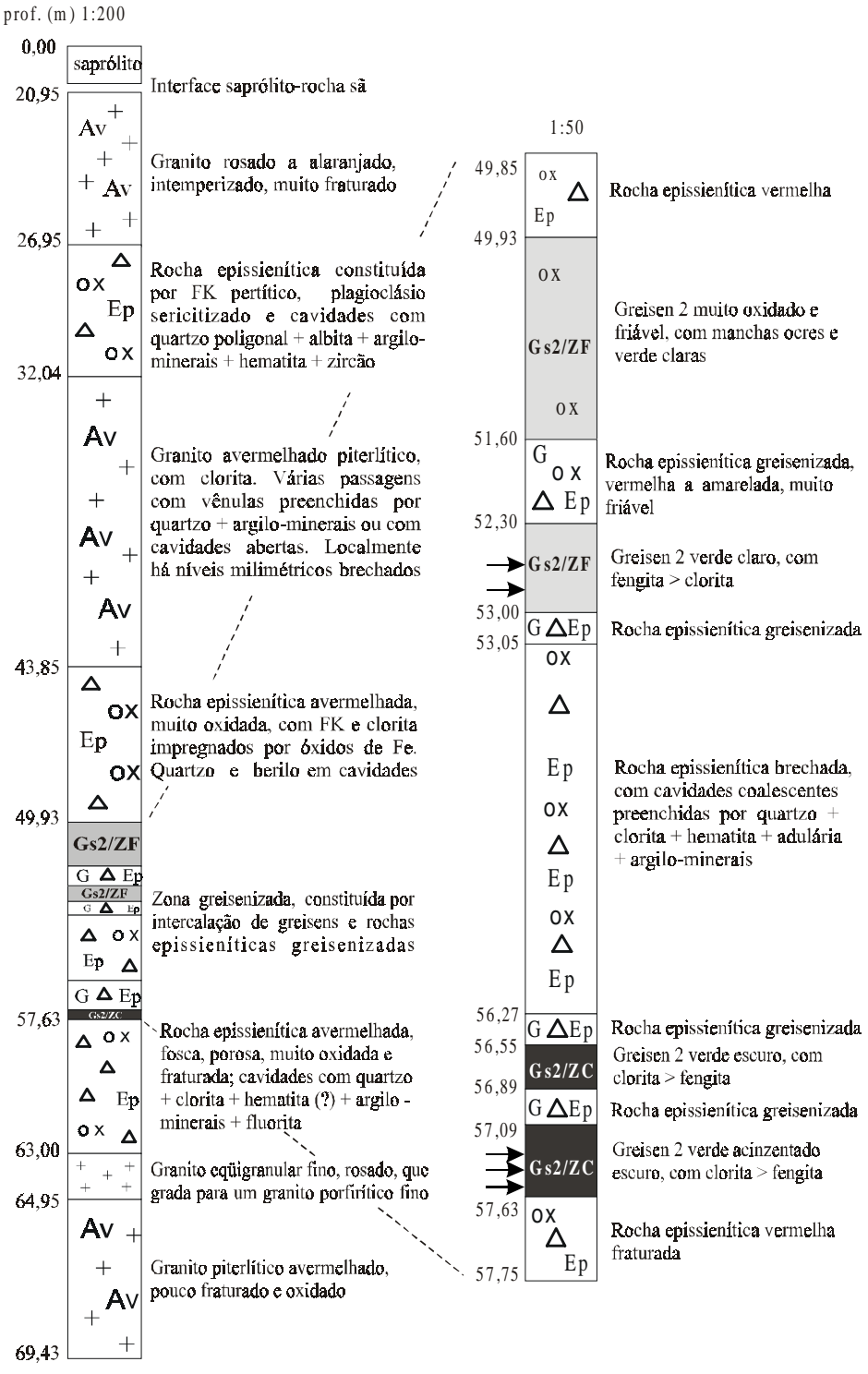

Figura 3 - Perfil esquemático do furo F12, representativo da zona de ocorrência do greisen 2. As setas indicam a localização das amostras com análise modal (ver Tab. 1). ZF: zona rica em fengita; ZC: zona rica em clorita; $G$ : rocha parcialmente greisenizada; ox: zona de oxidação intensa; Av: granito avermelhado, menos intensamente oxidado; Ep: zona de dominância de rocha epissienítica; triângulos: zona brechada ou com deformação rúptil. 
Régis Munhoz Krás Borges et al.

Tabela 1 - Composições modais de amostras representativas dos greisens 1 e 2 associados ao Granito Água Boa (Pitinga).

\begin{tabular}{|c|c|c|c|c|c|c|c|c|c|c|c|c|c|c|c|}
\hline Amostra & qzo & sid & feng & clor & top & fluo & cass & esf & sulf & $\begin{array}{c}\text { ana/ } \\
\text { rut }\end{array}$ & zir & carb & ber & Classificação & $\begin{array}{c}\text { Zona } \\
\text { mineralógica }\end{array}$ \\
\hline $\mathrm{F} 2 / 25,13$ & 74,3 & 19,2 & --- & tr. & 3,5 & tr. & tr. & 0,2 & 2,5 & 0,2 & 0,1 & ---- & ---- & top-sid-qzo Gs1 & siderofilita \\
\hline $\mathrm{F} 2 / 25,67$ & 71,3 & 4,2 & ---- & 0,4 & 15,3 & 0,8 & 0,4 & 4,9 & $1,7^{2}$ & 0,6 & 0,1 & ---- & ---- & sid-esf-top-qzo Gs1 & topázio \\
\hline$F 2 / 26,95$ & 78,9 & 15,7 & ---- & 0,1 & 3,8 & 0,7 & tr. & 0,5 & tr. & tr. & 0,3 & ---- & ---- & top-sid-qzo Gs1 & siderofilita \\
\hline $\mathrm{F} 2 / 27,15$ & 57,3 & 12,9 & ---- & tr. & 20,9 & tr. & 1,1 & 5,4 & $1,9^{2}$ & 0,2 & 0,1 & 0,1 & --- & esf-sid-top-qzo Gs1 & topázio \\
\hline $\mathrm{F} 2 / 27,25^{*}$ & 56,5 & 0,5 & 1,5 & 5,9 & 24,4 & 0,3 & 0,6 & 5,2 & 4,5 & 0,2 & 0,1 & 0,1 & ---- & esf-clor-top-qzo Gs1 & topázio \\
\hline $\mathrm{F} 2 / 27,34^{*}$ & 64,6 & 1,4 & ---- & 7,2 & 20,2 & 0,6 & 1,0 & 3,4 & 0,7 & 0,3 & 0,3 & tr. & --- & esf-clor-top-qzo Gs1 & topázio \\
\hline $\mathrm{F} 2 / 28,40$ & 63,5 & 13,0 & ---- & tr. & 14,0 & 0,7 & 0,4 & 4,1 & 0,9 & 0,7 & 0,5 & 2,2 & ---- & esf-sid-top-qzo Gs1 & GGxGs1 \\
\hline $\mathrm{F} 2 / 29,58$ & 63,0 & 22,0 & ---- & tr. & 11,6 & tr. & 1,0 & 0,6 & tr. & 0,1 & 0,3 & --- & ---- & top-sid-qzo Gs1 & siderofilita \\
\hline F13/43,66 & 45,0 & 38,7 & ---- & 1,2 & 8,7 & 3,1 & 0,5 & 0,8 & 0,1 & 0,9 & 1,0 & tr. & ---- & top-sid-qzo Gs1 & siderofilita \\
\hline $\mathrm{F} 13 / 43,90$ & 58,5 & 4,1 & 1,4 & 0,4 & 24,6 & 0,4 & 0,5 & 7,6 & 2,0 & 0,1 & 0,1 & ---- & --- & sid-esf-top-qzo Gs1 & topázio \\
\hline $\mathrm{F} 13 / 44,70$ & 48,2 & 3,2 & tr. & 3,6 & 35,2 & 1,6 & 0,8 & 6,2 & $0,4^{1}$ & 0,2 & 0,3 & ---- & ---- & sid-esf-top-qzo Gs1 & topázio \\
\hline $\mathrm{F} 13 / 45,70$ & 60,4 & 21,6 & ---- & 0,2 & 12,1 & 0,5 & 0,7 & 2,0 & $1,8^{1}$ & 0,2 & 0,2 & ---- & --- & esf-top-sid-qzo Gs1 & siderofilita \\
\hline $\mathrm{F} 13 / 45,80$ & 41,0 & 52,5 & ---- & tr. & 2,9 & 1,3 & 0,7 & 1,0 & tr. & $\operatorname{tr}$ & 0,6 & ---- & ---- & top-qzo-sid Gs1 & siderofilita \\
\hline F12/52,65 & 38,1 & ---- & 44,5 & 13,1 & ----- & --- & 1,9 & 0,2 & $2,1^{3}$ & ---- & 0,3 & ---- & tr. & clor-qzo-feng Gs2 & fengita \\
\hline F12/52,74 & 33,6 & ----- & 58,4 & 2,8 & ----- & --- & 3,2 & ---- & $1,9^{2}$ & tr. & 0,1 & ---- & ---- & qzo-feng Gs2 & fengita \\
\hline $\mathrm{F} 12 / 57,43$ & 32,1 & ----- & 7,4 & 32,5 & ----- & --- & 3,8 & --- & $23,4^{3}$ & --- & 0,6 & ---- & ---- & feng-pir-qzo-clor Gs2 & clorita \\
\hline $\mathrm{F} 12 / 57,50$ & 17,4 & ----- & 19,6 & 46,4 & ----- & --- & 2,5 & --- & $13,4^{2}$ & tr. & 0,7 & ---- & --- & pir-qzo-feng-clor Gs2 & clorita \\
\hline $\mathrm{F} 12 / 57,55$ & 30,3 & ---- & 3,8 & 55,3 & ----- & 0,2 & 3,2 & --- & $4,4^{2}$ & 0,6 & 1,0 & ---- & 0,9 & feng-pir-qzo-clor Gs2 & clorita \\
\hline $\mathrm{F} 9 / 32,28$ & 53,2 & ---- & 5,2 & 22,8 & ----- & --- & 3,7 & tr. & $13,8^{3}$ & 0,5 & 0,4 & ---- & --- & feng-pir-clor-qzo Gs2 & clorita \\
\hline $\mathrm{F} 9 / 32,38$ & 50,9 & ---- & 25,7 & 15,8 & ----- & ---- & 2,5 & ---- & 4,3 & 0,5 & 0,3 & ---- & ---- & clor-feng-qzo Gs2 & fengita \\
\hline F9/33,73 & 39,6 & ---- & 4,4 & 45,5 & ----- & ---- & 1,8 & ---- & $7,4^{2}$ & 0,5 & 0,6 & ---- & ---- & feng-pir-qzo-clor Gs2 & clorita \\
\hline $\mathrm{F} 9 / 34,00$ & 35,5 & ---- & 13,2 & 39,3 & ---- & ---- & 3,2 & ---- & $5,7^{2}$ & 1,2 & 0,9 & ---- & 0,8 & pir-feng-qzo-clor Gs2 & clorita \\
\hline
\end{tabular}

qzo: quartzo; sid: siderofilita; feng: fengita; clor: clorita; top: topázio; fluo: fluorita; cass: cassiterita; esf: esfalerita; sulf: pirita \pm calcopirita \pm galena; ana/rut: anatásio (Gs1) e rutilo (Gs2); zir: zircão; pir: pirita; carb: carbonato; ber: berilo;

*amostras próximas de veio com qzo + clor + sulf;

${ }^{1}$ predomínio de calcopirita sobre pirita;

${ }^{2}$ predomínio de pirita sobre calcopirita;

galena associada a pirita e calcopirita; tr.: traços.

GGxGs1: zona de contato de greisen 1 com granito greisenizado.

GREISEN2(GS2) O Gs2 tem textura granular média a fina, com variações locais para granulação mais grossa. Na zona greisenizada (ZG) do furo F12 (Fig. 3) há uma zonação mineral interna, definida principalmente pela sua distribuição espacial diferenciada ao longo do furo. Assim, no nível superior da ZG ocorre um greisen com predomínio de fengita sobre clorita (ZF), e no nível inferior predomina a clorita (ZC). Este subtipo rico em clorita também mostra um volume maior em sulfetos (Tabela 1).

No diagrama da figura 4, tanto as amostras da ZF quanto as da ZC se distribuem principalmente ao longo do campo IX, com algumas no campo V, e são classificadas como quartzo-mica-greisen, com variação para mica-quartzo-greisen. No caso específico do Gs2, o termo "mica" abrange os filossilicatos de maneira geral.

Uma feição textural característica deste greisen é a ocorrência de pseudomorfos sobre os componentes primários do granito. Os pseudomorfos são resquícios dos estágios iniciais de greisenização, sendo formados por fragmentos angulosos de feldspato alcalino, fraturados e hematitizados, substituídos por agregados minerais constituídos por quartzo, clorita, fengita e minerais opacos. Ademaix, o Gs2 apresenta uma grande densidade de fraturamentos, bem como um volume considerável de cavidades, abertas ou preenchidas, o que lhes confere um aspecto microscópico diferenciado, quando comparado ao Gs1.

O quartzo ocorre principalmente sob a forma de cristais poligonais, preenchendo cavidades drusiformes, com dimensões entre 0,4 e $4 \mathrm{~mm}$. Grãos anédricos ocorrem localmente.

A fengita tem leve pleocroísmo amarelo claro e incolor, e suas dimensões variam de 0,3 a $1 \mathrm{~mm}$. Ocorre como agregados lamelares a lamelar-radiados finos substituindo os componentes do granito primário ou em lamelas maiores, bem desenvolvidas, associada com clorita, e disposta paralelamente às clivagens.

A clorita é subédrica (0,4 a $1 \mathrm{~mm})$ e tem pleocroísmo em tons de verde. Além da associação com a fengita, ocorre em agregados em roseta que preenchem cavidades ou como pseudomorfos sobre K-feldspato.

A cassiterita ocorre disseminada na rocha, em grãos fraturados e alongados ( 0,3 a $0,7 \mathrm{~mm}$, localmente $3,5 \mathrm{~mm}$ ) em agregados. $\mathrm{O}$ mineral ocorre sob duas formas: (a) como grãos anédricos a subédricos, vermelho escuros a incolores, irregularmente zonados, seguidamente corroídos, associados a agregados finos de fengita e quartzo (ZF), e (b) como grãos subédricos a anédricos, vermelho claro a incolores, irregularmente zonados, localmente corroídos, associados a clorita, quartzo e pirita (ZC) (Costi et al. 2000b). Os seus conteúdos modais são maiores do que no Gs1 (Tab. 1).

A pirita atinge proporções modais expressivas em diversas amostras da ZC, que contém o maior volume de sulfetos. Em geral seus cristais são euédricos, em média com 0,6 mm, estando muitas vezes associados à cassiterita.

Em algumas amostras a galena ocorre em quantidades razoáveis, associada aos demais sulfetos. Normalmente apresenta pequenas inclusões arredondadas de calcopirita. Esta última também ocorre em grãos maiores, disseminados pela rocha.

$\mathrm{O}$ berilo ocorre em diminutos cristais euédricos a subédricos, associado ao quartzo como preenchimento de cavidades. Rutilo e zircão ocorrem em cristais finos, associados aos filossilicatos.

QUÍMICA MINERAL Métodos analíticos As análises químicas das micas dos greisens foram realizadas no Laboratório de 


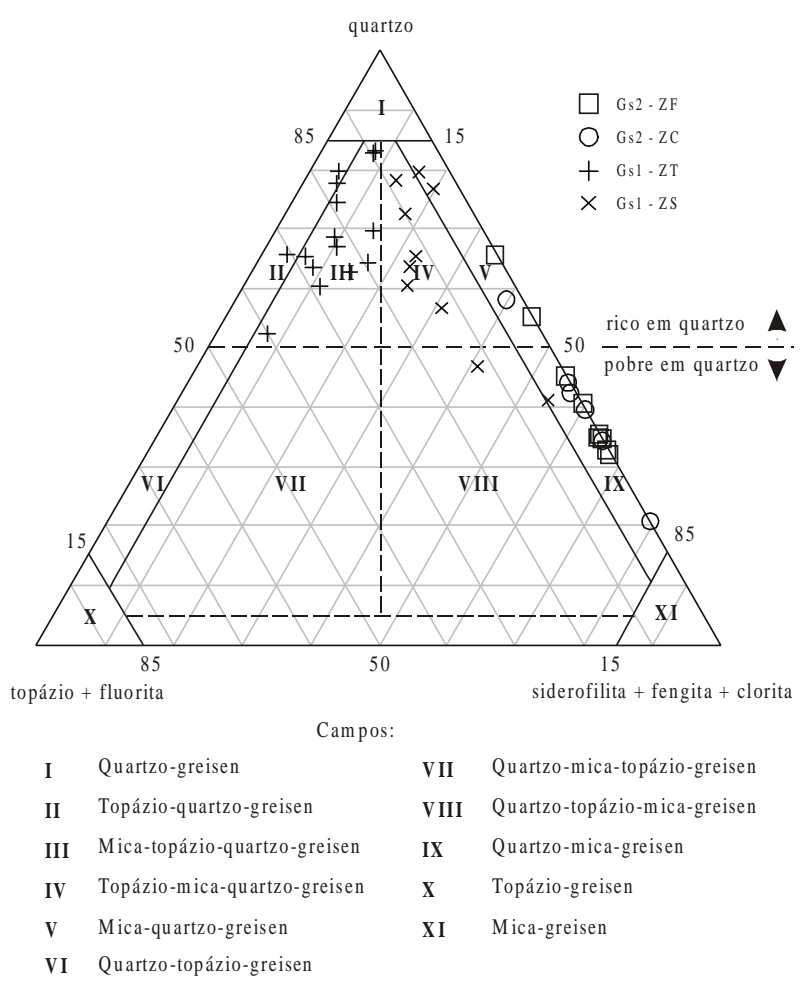

Figura 4 - Distribuição dos greisens associados ao Granito Água Boa no diagrama triangular de Kühne et al. (1972, modificado). Gs1: greisen 1; Gs2: greisen 2; ZS: zona rica em siderofilita; ZT: zona rica em topázio; $Z F$ : zona rica em fengita; $Z C$ : zona rica em clorita.

Microssonda Eletrônica do Instituto de Geociências da UnB, em uma microssonda eletrônica CAMECA SX-50 equipada com quatro espectrômetros WDS verticais e um EDS Kevex.

As condições operacionais utilizadas nas análises foram: tensão de aceleração de $15 \mathrm{Kv}$, corrente de feixe de $25 \mathrm{nA}$, diâmetro do feixe de $5 \mu \mathrm{m}$ e tempo de exposição do feixe de 10 segundos.

Micas trioctaédricas A Tabela 2 contem os dados de análises químicas representativas das micas trioctaédricas do Gs1 e suas fórmulas estruturais. A distribuição dos dados em diagramas de cátions (Fig. 5a-e) revela superposição composicional entre as pertencentes às ZT e ZS. No diagrama ${ }^{\mathrm{VI}} \mathrm{Al}$ x Fe/(Fe+Mg) (Fig. 5a; Guidotti 1984, modificado) foram lançados os pólos correspondentes às composições dos membros ideais Ann (annita), e Sid, $\mathrm{Sid}_{1}$ e $\mathrm{Sid}_{2}$ (variedades de siderofilita, conforme definidas em Sun $\&$ Yu 1999). A linha que une a Ann à $\mathrm{Sid}_{0}$ corresponde à de $\mathrm{Si}=6$ no triângulo Sid - Ann-Fe-Eas (Fe-Eastonita) do poliedro de Sun \& Yu (1999) (ver Fig. 7a). Assim, pela distribuição apresentada, as micas do Gs1 podem ser classificadas como siderofilita com moderado $\mathrm{Al}$ e variação composicional entre $\mathrm{Sid}_{1}$ e $\mathrm{Sid}_{0}$.

Dymek (1983) propôs diversas equações de substituição para explicar a evolução das micas trioctaédricas, dentre as quais se destacam:

$$
\begin{gathered}
\mathrm{VI}\left(\mathrm{R}^{2+}\right)+{ }^{\mathrm{IV}}\left(\mathrm{Si}^{4+}\right)={ }^{\mathrm{VI}}\left(\mathrm{Al}^{3+}\right)++^{\mathrm{IV}}\left(\mathrm{Al}^{3+}\right)(1) \\
3^{\mathrm{VI}}\left(\mathrm{R}^{2+}\right)=2^{\mathrm{VI}}\left(\mathrm{Al}^{3+}\right)+{ }^{\mathrm{VI}}(\mathrm{\square})(2)
\end{gathered}
$$

$A$ reação (1) corresponde à substituição tschermaquítica que envolve trocas de $\mathrm{Si}^{4+} \mathrm{e}^{\mathrm{VI}} \mathrm{Fe}^{2+}$ por ${ }^{\mathrm{IV}} \mathrm{Al} \mathrm{e}^{\mathrm{VI}} \mathrm{Al}$. Uma influência expressiva desta substituição nas micas estudadas deveria se re- fletir numa correlação positiva entre $\mathrm{Si}^{4+}$ e $\mathrm{Fe}^{2+}$, porém tal não se verifica (Fig. 5b), sugerindo que a mesma não exerceu um papel importante. A possível influência da reação (2) pode ser testada pela avaliação da correlação de ${ }^{\mathrm{VI}} \mathrm{Al}$ com $\mathrm{Fe}^{2+}$ (Fig. 5c) e com a ocupação octaédrica (Fig. 5d). ${ }^{\mathrm{VI}} \mathrm{Al} \mathrm{e} \mathrm{Fe}^{2+}$ mostram correlação negativa com razão próxima de 1:1,5, que é coerente com a equação (2). Além disso, o aumento de VI Al é acompanhado pelo aumento da vacância no sítio octaédrico, com razões próximas de 2:1 e 3:1 (Fig. 5d), igualmente coerentes em linhas gerais com a equação (2). A substituição sintetizada na equação (2), denominada de dioctaédrica-trioctaédrica por Dymek (1983) e de substituição muscovítica por Sun \& Yu (1999), certamente exerceu um papel determinante nas variações composicionais das micas trioctaédricas do Gs1. Portanto, as variações composicionais das siderofilitas do Gs1 foram fortemente influenciadas por uma substituição envolvendo trocas de $\mathrm{Fe}^{2+}$ por ${ }^{\mathrm{VI}} \mathrm{Al}$ com uma tendência de aumento paralelo da vacância no sítio octaédrico. Porém, esta substituição não explica a correlação negativa entre $\mathrm{Si}^{4+}$ e $\mathrm{Fe}^{2+}$ (Fig. 5b), nem a correlação positiva entre $\mathrm{Si}$ e $\mathrm{Al}$. Logo, as variações de $\mathrm{Si}$ podem ter auxiliado a compensar a carga negativa criada na camada octaédrica, mas isto não se deu devido à substituição acoplada de $\mathrm{Fe}^{2+}+\mathrm{Si}^{4+}$ por $\mathrm{Al}^{3+}$ e sim pelas trocas envolvendo $\mathrm{Si}^{4+} \mathrm{e} \mathrm{Fe}^{2+}$ que não podem ser explicadas pelas reações anteriores.

Por outro lado, um dos problemas na análise de micas trioctaédricas é a impossibilidade de efetuar dosagem de Li em microssonda eletrônica. A não dosagem deste elemento pode causar erros sistemáticos no cálculo de suas fórmulas estruturais, bem como a perda de importantes informações de caráter petrogenético. Conteúdos de até $2 \%$ deste óxido podem ser encontrados em siderofilitas (Tindle \& Webb 1990).

Para a obtenção de análises mais completas, uma alternativa é a determinação do Li por outros métodos, diretamente a partir de concentrados de micas (Moura \& Botelho 1994) ou pelo emprego de sonda iônica (Charoy et al. 1995). Para contornar as dificuldades analíticas, também foram desenvolvidos métodos para a estimativa dos conteúdos de lítio em micas (Monier \& Robert 1986b, Tindle \& Webb 1990, Tischendorf et al. 1997), aplicados por vários autores (Moura \& Botelho 1994, Costi 2000). Basicamente, o método consiste na estimativa do $\mathrm{Li}_{2} \mathrm{O}$ com base em equações de regressão linear pela correlação entre o $\mathrm{Li}_{2} \mathrm{O}$ determinado por via úmida e outros óxidos analisados por via úmida e/ou em microssonda eletrônica. No geral, são relevantes para o método as boas correlações positivas entre o $\mathrm{F}$ e o $\mathrm{Li}_{2} \mathrm{O}$, a boa correlação negativa entre o $\mathrm{FeO}_{\mathrm{t}}$ e o $\mathrm{Li}_{2} \mathrm{O}$ (substituição do ${ }^{\mathrm{VI}} \mathrm{Fe}^{2+}$ pelo $\mathrm{Li}$ ) e a excelente correlação positiva entre $\mathrm{SiO}_{2}$ e $\mathrm{Li}_{2} \mathrm{O}$. Segundo Foster (1960b), Monier \& Robert (1986b) e Charoy et al. (1995), para as micas trioctaédricas litiníferas contendo Fe, da série siderofilitazinnwaldita-polilitionita, a boa correlação $\mathrm{Li}_{2} \mathrm{O} \times \mathrm{SiO}_{2}$ é explicada pelo mecanismo de substituição:

$$
{ }^{\mathrm{VI}} \mathrm{Li}+{ }^{\mathrm{IV}} \mathrm{Si}={ }^{\mathrm{VI}}\left(\mathrm{Fe}^{2+}\right)+{ }^{\mathrm{IV}} \mathrm{Al}(3) \text {. }
$$

$\mathrm{O}$ exame das fórmulas estruturais das micas do Gs1, onde se observa uma ocupação octaédrica entre 4,93 e 5,49, e valores de $\mathrm{SiO}_{2}$ das análises similares àqueles das micas de $\mathrm{Fe}$-Li estudadas por Foster (1960b), sugere a existência de teores significativos de Li nas micas do Gs1. Em razão disto, os teores de Li dessas micas foram estimados pela equação: $\mathrm{Li}_{2} \mathrm{O}=\left(0,287 \times \mathrm{SiO}_{2}\right)-9,552$ (Tindle \& Webb 1990), resultando, de modo geral, teores de $\mathrm{Li}_{2} \mathrm{O}$ inferiores a $1 \%$ em peso (Tabela 2 ). A forte correlação negativa existente entre o $\mathrm{Fe}^{2+}$ e o Li calculado para as micas do Gs1 (Fig. 5e) sugere que o Li pode ter sido um componente importante nos mecanismos de substituição catiônica, segundo a equação (3) ou similares. 
Tabela 2 - Análises químicas representativas das micas dos greisens associados ao Granito Água Boa.

\begin{tabular}{|c|c|c|c|c|c|c|c|c|}
\hline \multirow[b]{3}{*}{ Amostra } & \multicolumn{8}{|c|}{ Micas trioctaédricas - Greisen 1} \\
\hline & \multicolumn{4}{|c|}{ Zona rica em topázio - ZT } & \multicolumn{4}{|c|}{ Zona rica em siderofilita-ZS } \\
\hline & \multicolumn{2}{|c|}{$\mathrm{F} 2 / 27,15$} & \multicolumn{2}{|c|}{$\mathrm{F} 14 / 51,75$} & \multicolumn{2}{|c|}{$\mathrm{F} 13 / 45,70$} & \multicolumn{2}{|c|}{$\mathrm{F} 7 / 43,72$} \\
\hline Análise & M1 & M2 & M3 & M4 & M5 & M6 & M7 & M8 \\
\hline $\mathrm{SiO}_{2}$ & 35,96 & 36,98 & 35,74 & 38,97 & 36,39 & 36,00 & 33,97 & 35,58 \\
\hline $\mathrm{TiO}_{2}$ & 1,58 & 1,38 & 1,64 & 1,05 & 0,25 & 0,41 & 1,29 & 1,14 \\
\hline $\mathrm{Al}_{2} \mathrm{O}_{3}$ & 17,90 & 19,17 & 19,22 & 20,82 & 20,65 & 20,24 & 17,66 & 18,68 \\
\hline $\mathrm{MgO}$ & 0,57 & 0,62 & 0,67 & 0,51 & 0,24 & 0,23 & 1,01 & 1,34 \\
\hline $\mathrm{CaO}$ & 0,04 & 0,04 & 0,01 & 0,00 & 0,00 & 0,02 & 0,02 & 0,00 \\
\hline $\mathrm{MnO}$ & 0,73 & 0,82 & 0,52 & 0,55 & 0,85 & 0,86 & 0,81 & 0,71 \\
\hline $\mathrm{FeO}$ & 27,51 & 25,16 & 25,79 & 21,59 & 24,09 & 25,82 & 28,25 & 27,01 \\
\hline $\mathrm{ZnO}$ & 0,00 & 0,00 & 0,00 & 0,14 & 0,13 & 0,01 & 0,01 & 0,15 \\
\hline $\mathrm{Na}_{2} \mathrm{O}$ & 0,14 & 0,08 & 0,10 & 0,10 & 0,16 & 0,19 & 0,15 & 0,10 \\
\hline $\mathrm{K}_{2} \mathrm{O}$ & 9,68 & 9,56 & 9,75 & 9,89 & 9,56 & 9,62 & 9,35 & 9,55 \\
\hline $\mathrm{Rb}_{2} \mathrm{O}$ & 0,85 & 0,87 & 0,81 & 0,85 & 0,96 & 0,87 & 0,78 & 0,91 \\
\hline $\mathrm{F}$ & 3,38 & 4,31 & 3,90 & 4,29 & 4,11 & 4,13 & 3,44 & 3,67 \\
\hline $\mathrm{Li}_{2} \mathrm{O}^{*}$ & 0,77 & 1,06 & 0,71 & 1,63 & 0,89 & 0,78 & 0,20 & 0,66 \\
\hline Total & 99,11 & 100,0 & 98,86 & 100,5 & 98,28 & 99,18 & 97,07 & 99,50 \\
\hline$-\mathrm{O}=\mathrm{F}$ & 1,42 & $1, \overline{8} 1$ & 1,64 & 1,81 & 1,73 & 1,74 & 1,45 & 1,54 \\
\hline Total & 97,69 & 98,24 & 97,22 & 98,70 & 96,55 & 97,44 & 95,62 & 97,96 \\
\hline
\end{tabular}

\begin{tabular}{|c|c|c|c|c|c|c|c|}
\hline \multicolumn{8}{|c|}{ Micas dioctaédricas - Greisen 2} \\
\hline \multicolumn{4}{|c|}{ Zona rica em fengita $-\mathrm{ZF}$} & \multirow{2}{*}{\multicolumn{4}{|c|}{$\begin{array}{c}\text { Zona rica em clorita - ZC } \\
\mathrm{F} 9 / 33,90\end{array}$}} \\
\hline & F12/ & 2,65 & & & & & \\
\hline M9 & M10 & M11 & M12 & M13 & M14 & M15 & M16 \\
\hline 46,62 & 46,05 & 47,45 & 47,01 & 46,10 & 46,47 & 44,54 & 44,87 \\
\hline 0,00 & 0,03 & 0,04 & 0,05 & 0,12 & 0,05 & 0,00 & 0,06 \\
\hline 30,59 & 31,42 & 30,87 & 32,29 & 29,06 & 30,09 & 31,65 & 29,75 \\
\hline 0,89 & 0,81 & 0,50 & 0,52 & 0,09 & 0,26 & 0,09 & 0,13 \\
\hline 0,00 & 0,00 & 0,01 & 0,03 & 0,00 & 0,01 & 0,00 & 0,00 \\
\hline 0,11 & 0,05 & 0,00 & 0,00 & 0,16 & 0,18 & 0,18 & 0,22 \\
\hline 5,79 & 5,71 & 4,99 & 4,34 & 7,72 & 5,74 & 5,08 & 6,33 \\
\hline 0,07 & 0,04 & 0,00 & 0,00 & 0,00 & 0,02 & 0,04 & 0,19 \\
\hline 0,09 & 0,08 & 0,08 & 0,06 & 13 & 0,10 & 0,10 & 0,14 \\
\hline 11,39 & 11,35 & 10,89 & 10,86 & 10,92 & 10,99 & 10,94 & 10,72 \\
\hline 0,12 & 0,16 & 0,16 & 0,21 & 0,42 & 0,27 & 0,09 & 0,16 \\
\hline 0,96 & 0,91 & 0,49 & 0,27 & 1,57 & 1,28 & 1,35 & 1,02 \\
\hline 0,37 & 0,34 & 0,15 & 0,07 & 0,71 & 0,54 & 0,58 & 0,40 \\
\hline 97,00 & 96,95 & 95,63 & 95,71 & 97,00 & 96,00 & 94,64 & 93,99 \\
\hline 0,40 & 0,38 & 0,21 & 0,11 & 0,66 & 0,54 & 0,56 & 0,43 \\
\hline 96,60 & 96,57 & 95,42 & 95,60 & 96,34 & 95,46 & 94,08 & 93,56 \\
\hline
\end{tabular}

Fórmula estrutural calculada em base a 22 átomos de oxigênio

\begin{tabular}{|c|c|c|c|c|c|c|c|c|c|c|c|c|c|c|c|c|}
\hline $\mathrm{Si}$ & 5,708 & 5,759 & 5,658 & 5,884 & 5,746 & 5,686 & 5,588 & 5,630 & 6,339 & 6,261 & 6,449 & 6,352 & 6,372 & 6,395 & 6,206 & 6,324 \\
\hline${ }^{\mathrm{IV}} \mathrm{Al}$ & 2,292 & 2,241 & 2,342 & 2,116 & 2,254 & 2,314 & 2,412 & 2,370 & 1,661 & 1,739 & 1,551 & 1,648 & 1,628 & 1,605 & 1,794 & 1,676 \\
\hline${ }^{\mathrm{VI}} \mathrm{Al}$ & 1,057 & 1,278 & 1,244 & 1,590 & 1,588 & 1,453 & 1,012 & 1,115 & 3,240 & 3,296 & 3,393 & 3,494 & 3,107 & 3,275 & 3,402 & 3,266 \\
\hline $\mathrm{Ti}$ & 0,189 & 0,162 & 0,195 & 0,119 & 0,030 & 0,049 & 0,159 & 0,135 & 0,000 & 0,003 & 0,005 & 0,006 & 0,013 & 0,006 & 0,000 & 0,006 \\
\hline $\mathrm{Mg}$ & 0,136 & 0,144 & 0,157 & 0,115 & 0,057 & 0,054 & 0,249 & 0,316 & 0,182 & 0,164 & 0,101 & 0,105 & 0,019 & 0,053 & 0,020 & 0,028 \\
\hline Mn & 0,099 & 0,109 & 0,070 & 0,070 & 0,113 & 0,115 & 0,113 & 0,095 & 0,013 & 0,006 & 0,000 & 0,000 & 0,019 & 0,021 & 0,021 & 0,026 \\
\hline $\mathrm{Fe}$ & 3,652 & 3,277 & 3,415 & 2,726 & 3,181 & 3,409 & 3,886 & 3,575 & 0,658 & 0,650 & 0,567 & 0,491 & 0,893 & 0,660 & 0,592 & 0,746 \\
\hline $\mathrm{Zn}$ & 0,000 & 0,000 & 0,000 & 0,016 & 0,015 & 0,001 & 0,002 & 0,018 & 0,007 & 0,004 & 0,000 & 0,000 & 0,000 & 0,002 & 0,004 & 0,019 \\
\hline $\mathrm{Li}$ & 0,490 & 0,665 & 0,449 & 0,991 & 0,567 & 0,497 & 0,130 & 0,419 & 0,203 & 0,189 & 0,084 & 0,036 & 0,396 & 0,302 & 0,327 & 0,229 \\
\hline Sítio O & 5,623 & 5,635 & 5,531 & 5,628 & 5,550 & 5,578 & 5,551 & 5,673 & 4,303 & 4,310 & 4,150 & 4,132 & 4,446 & 4,319 & 4,366 & 4,320 \\
\hline $\mathrm{Ca}$ & 0,006 & 0,007 & 0,001 & 0,000 & 0,000 & 0,005 & 0,004 & 0,000 & 0,000 & 0,000 & 0,003 & 0,005 & 0,000 & 0,000 & 0,000 & 0,000 \\
\hline $\mathrm{Na}$ & 0,043 & 0,025 & 0,029 & 0,028 & 0,050 & 0,060 & 0,048 & 0,031 & 0,025 & 0,021 & 0,023 & 0,017 & 0,035 & 0,028 & 0,029 & 0,038 \\
\hline K & 1,960 & 1,901 & 1,969 & 1,903 & 1,925 & 1,937 & 1,963 & 1,928 & 1,975 & 1,969 & 1,889 & 1,871 & 1,926 & 1,931 & 1,945 & 1,927 \\
\hline $\mathrm{Rb}$ & 0,099 & 0,087 & 0,083 & 0,083 & 0,097 & 0,088 & 0,083 & 0,093 & 0,010 & 0,014 & 0,014 & 0,019 & 0,037 & 0,024 & 0,008 & 0,015 \\
\hline Sítio A & 2,095 & 2,020 & 2,083 & 2,022 & 2,072 & 2,090 & 2,107 & 2,058 & 2,010 & 2,004 & 1,929 & 1,912 & 1,999 & 1,983 & 1,982 & 1,982 \\
\hline $\mathrm{F}$ & 1,696 & 2,121 & 1,953 & 2,048 & 2,053 & 2,066 & 1,789 & 1,836 & 0,412 & 0,389 & 0,212 & 0,112 & 0,685 & 0,557 & 0,594 & 0,455 \\
\hline
\end{tabular}

*Cálculo de $\mathrm{Li}_{2} \mathrm{O}$ segundo a equação $\mathrm{Li}_{2} \mathrm{O}=\left(0,287 \times \mathrm{SiO}_{2}\right)$ - 9,552 (Tindle \& Webb 1990), para as micas trioctaédricas, e

segundo a equação $\mathrm{Li}_{2} \mathrm{O}=0,3935 \times \mathrm{F}^{1,326}$ (Tischendorf et al. 1997) para as micas dioctaédricas.

As fórmulas estruturais das micas do Gs1 com o menor e o maior teor de $\mathrm{Li}_{2} \mathrm{O}$ calculado são, respectivamente:

$$
\left(\mathrm{K}_{1,96} \mathrm{Na}_{0,03} \mathrm{Rb}_{0,05}\right)_{2,04}\left[\left(\mathrm{Li}_{0,13} \mathrm{Fe}_{3,88}^{2+} \mathrm{Mg}_{0,25} \mathrm{Mn}_{(4), 12} \mathrm{Al}_{1,02} \mathrm{Ti}_{0,15}\right)_{5,55}\left(\mathrm{Al}_{2,42} \mathrm{Si}_{5,58}\right)_{8,00}\left(\mathrm{~F}_{1,79} \mathrm{OH}_{2,21}\right)\right]
$$

e

$$
\left.\left(\mathrm{K}_{1,90} \mathrm{Na}_{0,03} \mathrm{Rb}_{0,08}\right)_{201}\left[\mathrm{Li}_{0,99} \mathrm{Fe}_{2,73}^{2+} \mathrm{Mg}_{0,12} \mathrm{Mn}_{(5), 07} \mathrm{Al}_{1,59} \mathrm{Ti}_{0,12}\right)_{5,62}\left(\mathrm{Al}_{2,12} \mathrm{Si}_{5,88}\right)_{8,00}\left(\mathrm{~F}_{25} \mathrm{OH}_{1,5}\right)\right]
$$

A figura 6 a apresenta a distribuição das micas trioctaédricas do Gs1 no diagrama Li- $\mathrm{R}^{2+}-\mathrm{R}^{3+}$ de Foster (1960b). No diagrama, o pólo $\mathrm{Sid}_{0}$ corresponde ao mesmo tempo à siderofilita da série de micas de Fe-Li desta autora (campo 3 ) e à siderofilita ${ }_{0}$ de Sun \& Yu (1999). Os pólos $\mathrm{Sid}_{1}$ e $\mathrm{Sid}_{2}$ correspondem a variedades de siderofilita com conteúdos menores de ${ }^{\mathrm{VI}} \mathrm{Al}$ do que a $\operatorname{Sid}_{0}$ (Sun \& Yu 1999). As micas estudadas foram plotadas ainda no diagrama
Li-Al-M²+ (Monier \& Robert 1986b), onde também se situam nos pólos correspondentes à $\mathrm{Sid}_{0}, \mathrm{Sid}_{1}$ e $\mathrm{Sid}_{2}$ (Fig. 6b). Em ambos diagramas, as micas trioctaédricas do Gs1 situam-se próximo da linha que define a série siderofilita 1 -trilitionita, distinguindo-se das micas desta série por serem ligeiramente mais ricas em $\mathrm{Li}$.

A grande complexidade das séries de micas ferrosas litiníferas fica muito bem evidenciada nos trabalhos de Cerný \& Burt (1984) e Sun \& Yu (1999). Os últimos autores propuseram um arcabouço geométrico para micas litiníferas ferrosas ideais. Na figura 7a é mostrado o comportamento das micas trioctaédricas do Gs1, representadas pelas suas composições com teores mínimo e máximo de $\mathrm{Li}$ [fórmulas (4) e (5)], rebatidas no plano $\mathrm{Li}=0$ do poliedro proposto por Sun \& Yu (1999). A composição mais pobre em Li (quadrado), e a mais rica em Li (círculo), situam-se entre $\operatorname{Sid}_{1}$ e $\mathrm{Sid}_{0}$ 

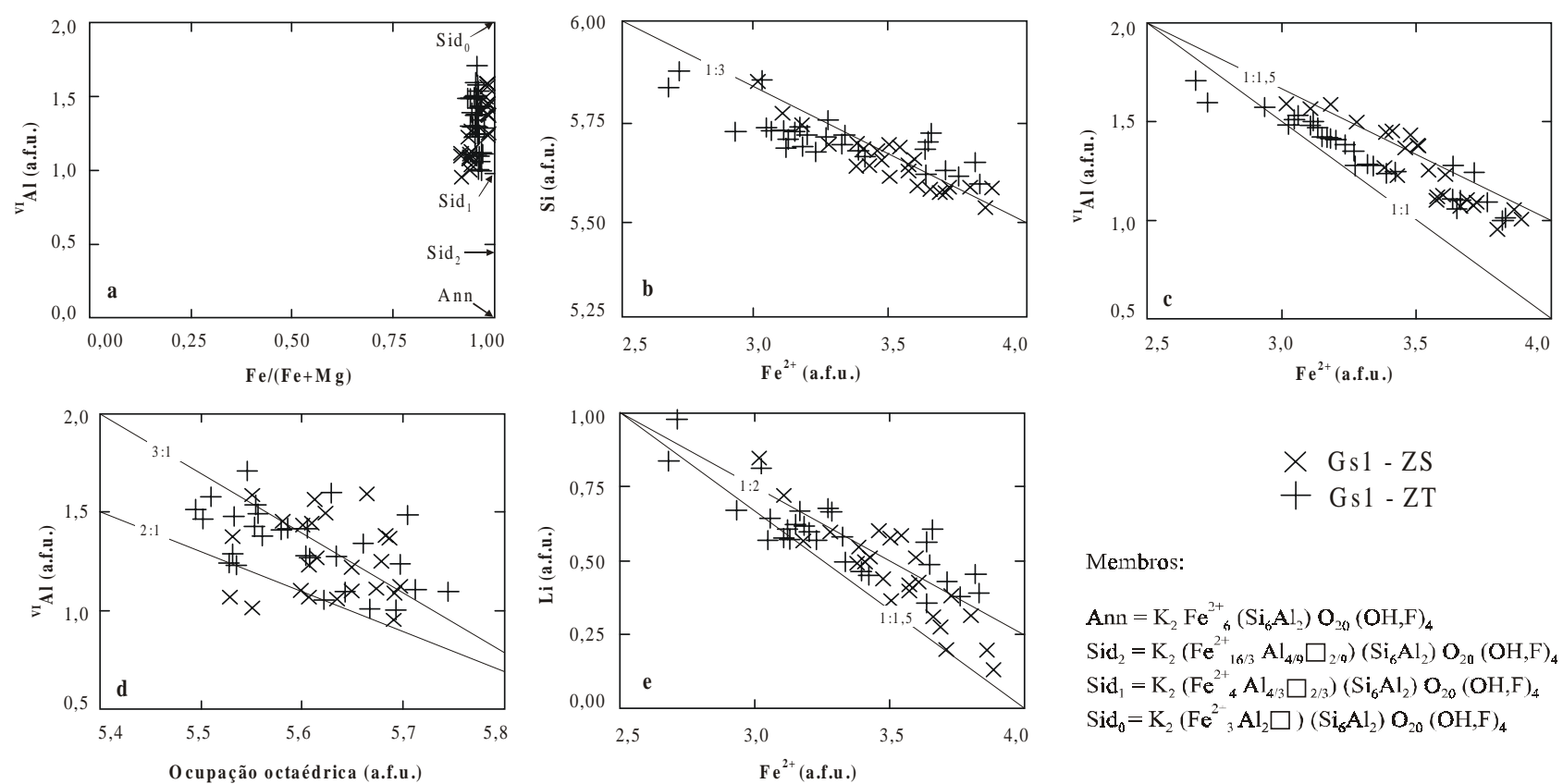

Membros:

$\mathrm{Ann}=\mathrm{K}_{2} \mathrm{Fe}^{2+}\left(\mathrm{Si}_{6} \mathrm{Al}_{2}\right) \mathrm{O}_{20}(\mathrm{OH}, \mathrm{F})_{4}$

$\mathrm{Sid}_{2}=\mathrm{K}_{2}\left(\mathrm{Fe}^{2+}{ }_{16 / 3} \mathrm{Al}_{4 / 9} \square_{2 / 9}\right)\left(\mathrm{Si}_{6} \mathrm{Al}_{2}\right) \mathrm{O}_{20}(\mathrm{OH}, \mathrm{F})_{4}$

$\mathrm{Sid}_{1}=\mathrm{K}_{2}\left(\mathrm{Fe}^{2+}{ }_{4} \mathrm{Al}_{4 / 3} \square_{2 / 3}\right)\left(\mathrm{Si}_{6} \mathrm{Al}_{2}\right) \mathrm{O}_{20}(\mathrm{OH}, \mathrm{F})_{4}$

$\mathrm{Sid}_{0}=\mathrm{K}_{2}\left(\mathrm{Fe}^{2+}{ }_{3} \mathrm{Al}_{2} \square\right)\left(\mathrm{Si}_{6} \mathrm{Al}_{2}\right) \mathrm{O}_{20}(\mathrm{OH}, \mathrm{F})_{4}$

Figura 5 - a) Distribuição das micas trioctaédricas do greisen 1 no diagrama ${ }^{V I} \mathrm{Al}$ x $\mathrm{Fe} /(\mathrm{Fe}+\mathrm{Mg})$ de Guidotti (1984, modificado). Membros conforme Sun \& Yu (1999): Ann: annita; Sid, Sid, Sid, variedades de siderofilita. b) até e) diagramas de correlação de cátions das micas estudadas. ZS: zona rica em siderofilita; ZT: zona rica em topázio. a.f.u: átomos por fórmula unitária.

e muito próximas da linha $\mathrm{Sid}_{0}$-Annita, mostrando, porém, um ligeiro empobrecimento em $\mathrm{Si}$. O diagrama indica que as substituições nas micas estudadas tenderiam a aproximá-las da composição da $\mathrm{Sid}_{0}$, seguindo o trend da substituição muscovítica, porém, como ao mesmo tempo elas se enriqueciam em $\mathrm{Li}$, seguiram na realidade a junta Sid -trilitionita (Fig. 6a).

$\mathrm{O}$ diagrama da figura $7 \mathrm{~b}$ esquematiza o espaço composicional $\mathrm{K}-\mathrm{Li}-\mathrm{Fe}-\mathrm{Al}-\mathrm{Si}$ para micas litiníferas trioctaédricas com ${ }^{\mathrm{VI}}(\square)=0$, conforme Cerný \& Burt (1984). No diagrama, a seta indica a variação composicional entre termos mais pobre e mais rico em Li das micas analisadas. Apesar dos pontos plotados não corresponderem rigorosamente às fórmulas químicas obtidas, sobretudo porque os conteúdos de Li das micas do Gs1 são bem inferiores aos sugeridos pelo diagrama, eles permitem observar o trend de substituição com a participação do Li que teria influenciado a evolução destas micas. Essa não correspondência total pode, em parte, ser explicada pelo fato de que a equação (3), base para o cálculo do Li, não descreve a solução sólida sid -trilitionita, em que a variação de Si é muito pequena. Assim, a equação de Tindle \& Webb (1990) subestima o Li das micas do Gs1. Os vetores assinalados no canto superior esquerdo da figura $7 \mathrm{~b}$ indicam os principais mecanismos de substituição sugeridos por Cerný \& Burt (1984) neste espaço composicional. $\mathrm{O}$ vetor mais escuro é o mecanismo de substituição com a participação do Li sugerido para as micas do Gs1. Este trend é intermediário entre o representado pelas equações (6) e (7), mas aproxima-se mais daquele da equação (6):

com $\mathrm{Al}$ total constante, $\mathrm{e}$

$$
2 \mathrm{Li}+\mathrm{Si}+\mathrm{Al}^{\mathrm{VI}}=3 \mathrm{Fe}^{2+}+\mathrm{Al}^{\mathrm{VV}}(6)
$$

$$
\mathrm{Li}+\mathrm{Al}^{\mathrm{VI}}=2 \mathrm{Fe}^{2+}(7)
$$

com $\mathrm{Si}$ constante.

Ambas equações podem ser combinadas resultando:

$$
3 \mathrm{Li}+\mathrm{Si}+2 \mathrm{Al}^{\mathrm{VI}}=5 \mathrm{Fe}^{2+}+\mathrm{Al}^{\mathrm{V}}(8)
$$

Equações similares são propostas por Sun \& Yu (1999):

$$
\begin{aligned}
& { }^{\mathrm{IV}} \mathrm{R}^{3+}+3^{\mathrm{VI}} \mathrm{R}^{2+}=\mathrm{Si}+{ }^{\mathrm{VI}} \mathrm{R}^{3+}+2 \mathrm{Li} \quad(9), \mathrm{e} \\
& 2^{\mathrm{IV}} \mathrm{Al}+4 \mathrm{Fe}^{2+}=2 \mathrm{Si}+{ }^{\mathrm{VI}} \mathrm{Al}+3 \mathrm{Li} \quad(10) .
\end{aligned}
$$

As equações (8), (9) e (10) explicariam a correlação negativa entre $\mathrm{Si}$ e $\mathrm{Fe}^{2+}$ e positiva com o ${ }^{\mathrm{VI}} \mathrm{Al}$ no caso das micas estudadas. Porém, os conteúdos de Li das micas do Gs1 parecem nitidamente inferiores aos sugeridos por estas equações. Isto se deve ao fato que a substituição muscovítica, representada pela equação (2), que não envolve o Li, exerceu uma influência tão ou mais importante que as das equações acima nas substituições. Uma equação alternativa, levando em conta os aspectos mencionados, seria:

$$
\mathrm{Li}+{ }^{\mathrm{IV}}\left(\mathrm{Si}^{4+}\right)+2^{\mathrm{VI}}\left(\mathrm{Al}^{3+}\right)+{ }^{\mathrm{VI}}(\mathrm{\square})=4^{\mathrm{VI}}\left(\mathrm{Fe}^{2+}\right)+{ }^{\mathrm{IV}}\left(\mathrm{Al}^{3+}\right)(11) \text {. }
$$

Este mecanismo de substituição é intermediário entre os vetores de substituição Fe-eastonita-trilitionita (ET) e annita-trilitionita (AT) de Sun \& Yu (1999), mas não parece se enquadrar perfeitamente nos diversos vetores definidos por estes mesmos autores. Ele se aproxima mais do vetor ET, porém ao invés da Fe-eastonita deveria ser considerada uma série partindo da siderofilita no caso específico das micas do Gs1. Também deve ser considerado que as limitações na definição dos conteúdos de Li e seus baixos teores não contribuem para uma definição mais rigorosa da série.

Micas dioctaédricas A Tabela 2 contem os resultados analíticos representativos das micas dioctaédricas do Gs2, juntamente com suas fórmulas estruturais.

Foster (1960a) demonstrou que, nas micas dioctaédricas com estrutura de muscovita, a substituição de um cátion trivalente por um bivalente, íon por íon, gera uma carga negativa na camada octaédrica, balanceada por um aumento relativo na carga positiva da camada tetraédrica, pela substituição de ${ }^{\mathrm{IV}} \mathrm{Al}$ por $\mathrm{Si}$, segundo a equação (1). Essa reação de substituição preserva a carga da camada composta, que é compensada pela carga positiva do sítio 

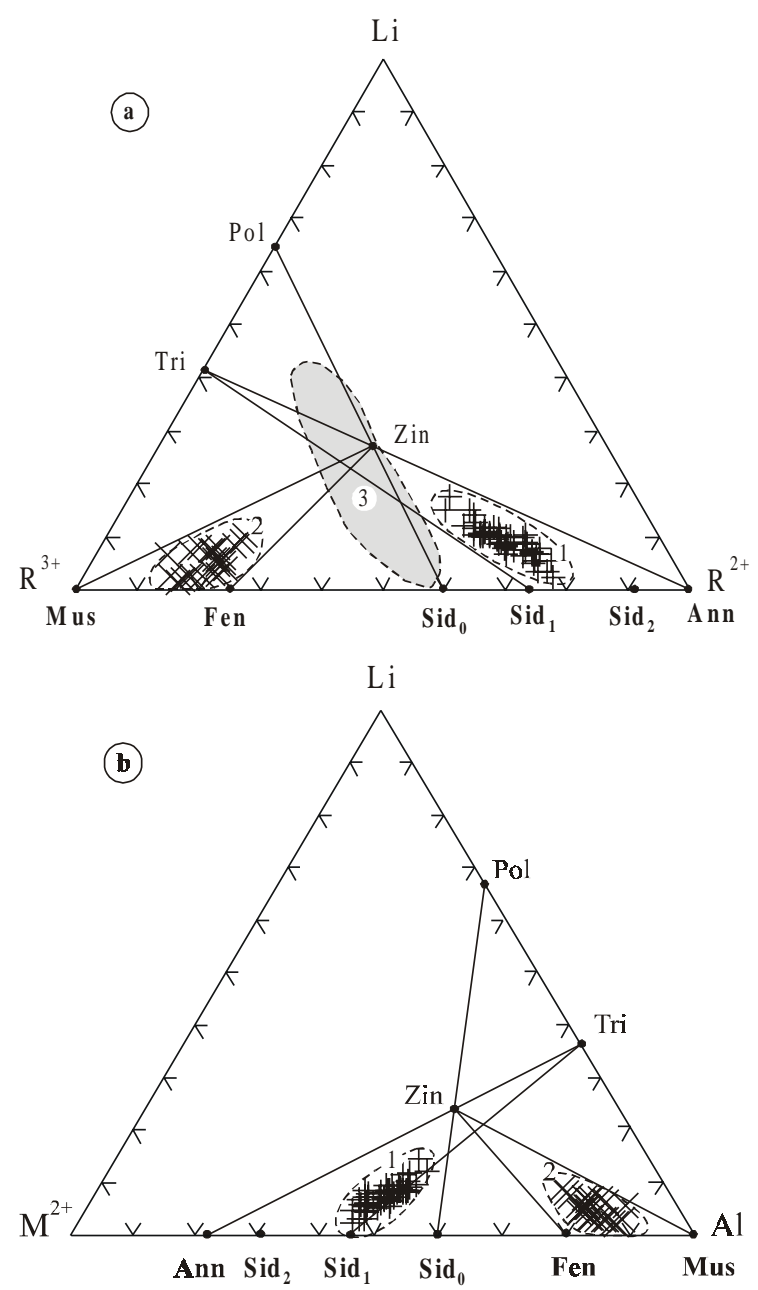

Figura 6 - Distribuição das micas trioctaédricas e dioctaédricas dos greisens estudados: a. no diagrama $L i-R^{2+}-R^{3+}$ (Foster $1960 b$, modificado); b. no diagrama $\mathrm{Li}-\mathrm{Al}-\mathrm{M}^{2+}$ (Monier \& Robert 1986b, modificado). Campos: 1: micas trioctaédricas do Gs1 (símbolo +); 2: micas dioctaédricas do greisen 2 (símbolo $X)$; 3: série siderofilita-polilitionita (Foster 1960b). $M^{2+}=R^{2+}=F e^{2+}+M g+M n ; R^{3+}={ }^{V l} A l+T i^{4+} ; A l={ }^{I V} A l+{ }^{V I} A l ; A n n=$ annita; $P$ Pol = polilitionita $;$ Tri = trilitionita $;$ Zin = zinnwaldita; Fen = fengita $;$ Mus = muscovita $;$ Sid $_{0}$ Sid, Sid $_{2}=$ variedades de siderofilita, conforme Sun \& Yu (1999). Os pontos da Zin e Tri correspondem, na verdade, aos pólos dos membros ideais zinnwaldita e trilitionita, conforme o poliedro de Sun \& Yu (1999), projetados no plano do diagrama de Foster (1960b).

intercamada.

Monier \& Robert (1986a) apresentam os resultados de um estudo experimental de soluções sólidas de muscovita no sistema $\mathrm{K}_{2} \mathrm{O}$ $\mathrm{M}^{2+} \mathrm{O}-\mathrm{Al}_{2} \mathrm{O}_{3}-\mathrm{SiO}_{2}-\mathrm{H}_{2} \mathrm{O}-(\mathrm{HF})$, onde $\mathrm{M}^{2+}=\mathrm{Mg}^{2+}$ ou Fe ${ }^{2+}$, no intervalo de 300 a $700^{\circ} \mathrm{C}$, a 2 kbar de $\mathrm{P}_{\mathrm{H} 2 \mathrm{O}}$. O sistema ferroso foi estudado em menor detalhe que o magnesiano, limitando-se às juntas muscovita-annita e muscovita-celadonita a temperaturas de $600^{\circ}$ e $400^{\circ} \mathrm{C}$ e $\mathrm{P}_{\mathrm{H} 2 \mathrm{O}}=2 \mathrm{Kbar}$. A extensão do domínio de solução sólida da muscovita é muito mais restrita no sistema ferroso do que no magnesiano, considerando-se temperaturas idênticas. Soluções sólidas de muscovita podem ser descritas, nesse sistema, como o resultado de duas substituições. Uma é a substituição fengítica
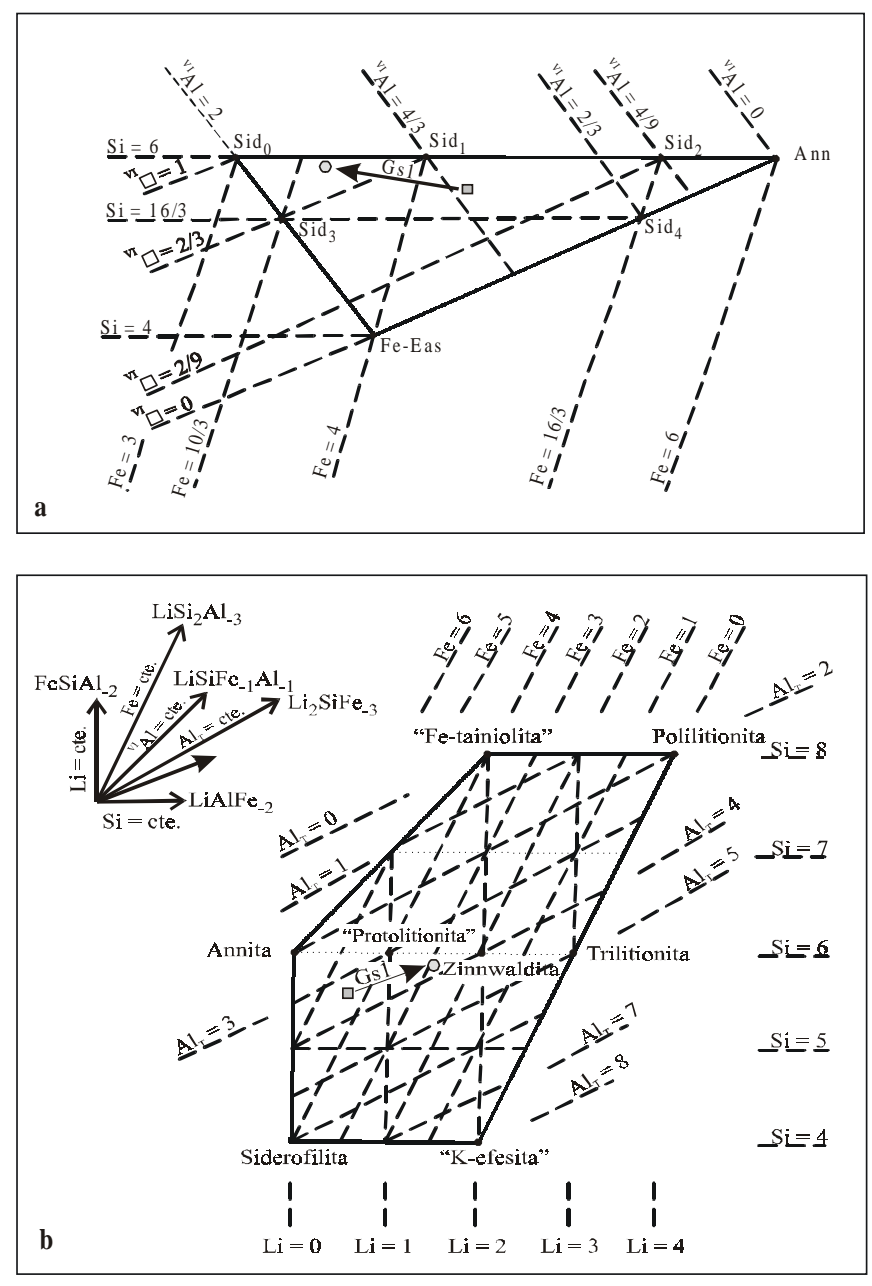

Figura 7 - Comportamento das micas trioctaédricas do Gs1: a. no poliedro das micas de Fe-Al-Li (Sun \& Yu 1999, simplificado). O triângulo Ann-Fe-Eas-Sid 0 representa as micas trioctaédricas no plano composicional Li=0. Ann: annita; $\mathrm{Sid}_{0}, \mathrm{Sid}_{1}, \mathrm{Sid}_{2}, \mathrm{Sid}_{3}$, $\mathrm{Sid}_{4}$, Fe-Eas: variedades de siderofilita; ${ }^{V I} \square$ : vacâncias octaédricas. b. no diagrama de Cerný \& Burt (1984). Li, Si, Al $\left({ }^{V I} \mathrm{Al}+{ }^{I V} \mathrm{Al}\right), \mathrm{Fe}\left(\mathrm{Fe}^{2+}+\mathrm{Mn}+\mathrm{Mg}\right):$ total de cátions desses elementos. $O$ vetor mais escuro no canto superior esquerdo representa o mecanismo substitucional assumido para as micas analisadas. Em ambos diagramas, o quadrado representa a composição aproximada do termo mais pobre em Li, enquanto que o círculo representa a composição do termo mais enriquecido em Li das micas analisadas neste estudo.

(x), a qual preserva o caráter dioctaédrico puro da mica; a segunda é a substituição biotítica (y), a qual leva no sentido de uma estrutura trioctaédrica e não muda a composição da camada tetraédrica $\mathrm{Si}_{3} \mathrm{Al}$ (Fig. 8e). Nesse sistema, considerando-se meia célula, a fórmula estrutural geral da muscovita é:

$$
\mathrm{K}\left(\mathrm{Al}_{2-x-2 y / 3} \mathrm{M}^{2+}{ }_{x+y} \square_{1-y / 3}\right)\left(\mathrm{Si}_{3+x} \mathrm{Al}_{1-x}\right) \mathrm{O}_{10}(\mathrm{OH})_{2}(12) \text {. }
$$

As micas brancas naturais sem lítio são geralmente descritas como soluções sólidas entre um membro final muscovita:

$$
\mathrm{K}_{2}\left(\mathrm{Al}_{4} \square_{2}\right)\left(\mathrm{Si}_{6} \mathrm{Al}_{2}\right) \mathrm{O}_{20}(\mathrm{OH})_{4}(13) \text {, }
$$

onde representa os sítios octaédricos vagos, e um membro final celadonita (ou Fe-Al-celadonita):

$$
\mathrm{K}_{2}\left(\mathrm{Al}_{2} \mathrm{M}_{2}^{2+} \mathrm{\square}_{2}\right) \mathrm{Si}_{8} \mathrm{O}_{20}(\mathrm{OH})_{4}(14)
$$


com $\mathrm{M}^{2+}=\mathrm{Mg}^{2+}$ e/ou $\mathrm{Fe}^{2+}$, correspondendo à denominada série fengítica. O termo intermediário desta série é a fengita, com fórmula ideal:

$$
\mathrm{K}_{2}\left(\mathrm{Fe}^{2+} \mathrm{Al}_{3} \square_{2}\right)\left(\mathrm{Si}_{7} \mathrm{Al}\right) \mathrm{O}_{20}(\mathrm{OH})_{4}(15)
$$

De modo análogo ao das micas trioctaédricas, alguns autores também desenvolveram métodos para estimar indiretamente as concentrações de Li em micas dioctaédricas, a partir de análises em microssonda eletrônica, por abordagens empíricas baseadas em correlações de elementos. Tischendorf et al. (1997), a partir de uma compilação na literatura de análises químicas em micas dioctaédricas, não observaram variação sistemática do $\mathrm{Li}_{2} \mathrm{O}$ com $\mathrm{Al}_{2} \mathrm{O}_{3}$ ou $\mathrm{SiO}_{2}$, mas demonstraram que o $\mathrm{F}$ mostra uma boa correlação positiva com o Li. Apresentaram, em razão disso, uma equação para o cálculo de Li a partir das concentrações de F obtidas em análises de microssonda eletrônica:

$$
\mathrm{Li}_{2} \mathrm{O}=0,3935 \mathrm{xF}^{1,326}(16) \text {. }
$$

Como as micas dioctaédricas utilizadas no estudo de Tischendorf et al. (1997) apresentam muitas similaridades composicionais com as micas do Gs2, optou-se pelo cálculo do $\mathrm{Li}_{2} \mathrm{O}$ segundo a equação (16), apesar das dificuldades analíticas para uma perfeita dosagem do F em microssonda eletrônica. Ainda assim, os teores de $\mathrm{Li}_{2} \mathrm{O}$ resultantes são muito baixos (Tabela 2), sugerindo uma presença muito restrita de Li nestas micas.

A análise conjunta das fórmulas estruturais das micas do greisen 2 e de alguns diagramas de correlação entre cátions demonstra que a substituição de ${ }^{\mathrm{VI}} \mathrm{Al}$ pelo $\mathrm{Fe}^{2+}$ (Fig. 8a) é o principal mecanismo de acomodação de cátions nos sítios octaédricos destas micas. $\mathrm{O}$ diagrama $\mathrm{Fe}^{2+}+\mathrm{Si}$ vs ${ }^{\mathrm{VI}} \mathrm{Al}+{ }^{\mathrm{IV}} \mathrm{Al}$ (Fig. 8b) revela a importância da substituição fengítica ou tschermaquítica na evolução das micas dioctaédricas do Gs2. Por outro lado, a correlação negativa observada no diagrama $\mathrm{Li} \mathrm{x}{ }^{\mathrm{VI}} \mathrm{Al}$ (Fig. 8c) sugere um aumento na ocupação do Li à medida que o ${ }^{\mathrm{VI}} \mathrm{Al}$ é substituído pelo $\mathrm{Fe}^{2+}$ na camada octaédrica dessas micas.

No diagrama Al-M ${ }^{2+}-\mathrm{Si}$ (Monier \& Robert 1986a) as micas do Gs2 se colocam a meio caminho entre os pólos da muscovita e da fengita (Fig. 8e). Esta distribuição segundo um alinhamento paralelo à junção $\mathrm{Mu}$ - Cel é resultante não somente dos mecanismos de substituição fengítica, mas também do aumento na ocupação octaédrica, que poderia refletir teores de Li crescentes, mas muito mais provavelmente se deve à contribuição da substituição biotítica.

Assim, as micas dioctaédricas do Gs2 podem ser classificadas como fengitas, possivelmente contendo pequenos teores de Li. As fórmulas estruturais utilizadas nos vários diagramas de termos com o menor e o maior teor de Li calculado são, respectivamente: $\left(\mathrm{K}_{1,87} \mathrm{Na}_{0,02} \mathrm{Rb}_{0,02}\right)_{1,91}\left[\left(\mathrm{Li}_{0,04} \mathrm{Fe}_{0,49}^{2+} \mathrm{Mg}_{0,10} \mathrm{Al}_{3,49}\right)_{4,13}\left(\mathrm{Al}_{1,65} \mathrm{Si}_{6,35}\right)_{8,00}\left(\mathrm{~F}_{0,11} \mathrm{OH}_{3,89}\right)\right]$ (19), e

$$
\left(\mathrm{K}_{1,94} \mathrm{Na}_{0,01} \mathrm{Rb}_{0,03}\right)_{1,98}\left[\left(\mathrm{Li}_{0,44} \mathrm{Fe}^{2+}\right)_{8,81} \mathrm{Mg}_{0,12} \mathrm{Al}_{3,06} \mathrm{Ti}_{0,04}\right)_{4,47}\left(\mathrm{Al}_{1,60} \mathrm{Si}\right.
$$

Segundo Monier \& Robert (1986́b), um dos mecanismos que explica a fixação do Li na estrutura das muscovitas é dado por:

$$
{ }^{\mathrm{VI}} \mathrm{Al}+{ }^{\mathrm{VI}}(\square)={ }^{\mathrm{VI}}\left(\mathrm{M}^{2+}\right)+{ }^{\mathrm{VI}} \mathrm{Li}(21) \text {, }
$$

o que modifica o caráter dioctaédrico puro da muscovita e preserva a sua camada tetraédrica. Nos diagramas $\mathrm{Li}-\mathrm{R}^{2+}-\mathrm{R}^{3+} \mathrm{e} \mathrm{Li}-\mathrm{Al}-\mathrm{M}^{2+}$ (Figs. 6a e 6b) as micas do greisen 2 plotam em um campo situado entre as séries muscovita-zinnwaldita e fengita-zinnwaldita. No entanto, os trends de enriquecimento global em $\mathrm{Fe}^{2+}$ e Si sugerem que as micas do Gs2 foram fortemente influenciadas pela substituição fengítica, pelo mecanismo da equação (1), enquanto que os teores de Li poderiam ser explicados em parte pela equação (21). Paralelamente a estes mecanismos substitucionais, a fengita do Gs2 apresenta um enriquecimento em $\mathrm{F}$ acoplado ao aumento do
$\mathrm{Fe}^{2+}$ em seus sítios octaédricos, tanto na ZF quanto na ZC (Fig. $8 \mathrm{~d}$ ), sendo que os maiores teores de F ocorrem nas micas da ZC.

DISCUSSÕES E CONSIDERAÇÕES FINAIS Composições modais dos greisens estudados e natureza dos fluidos A distribuição dos greisens estudados e suas diferentes zonas mineralógicas, em diagrama de seus principais constituintes minerais (Fig. 4), fornece informações sobre as atividades relativas de alguns constituintes dos fluidos responsáveis pela sua formação. Normalmente, greisens ocorrem em ambientes muito ricos em $\mathrm{SiO}_{2} \mathrm{eF}$, e uma vez que o último é facilmente incorporado em minerais como topázio, fluorita e micas, os seus conteúdos indicam a atividade do HF no meio formador. Os conteúdos de quartzo refletem a atividade da sílica na fase fluida, e a abundância de micas ( \pm clorita) pode ser indicativa da atividade do ion $\mathrm{H}^{+}$nos fluidos.

Uma das principais diferenças entre os dois greisens é a abundância de topázio no Gs1, principalmente na ZT, que sugere um ambiente de formação com maior $a H F$ do que o do Gs2. Por outro lado, o grande volume modal de filossilicatos no Gs2 indica maior disponibilidade do íon $\mathrm{H}^{+}$em solução, propiciando aumento das reações de hidrólise e conseqüente maior formação de minerais hidratados. O Gs1 é mais rico em quartzo do que o Gs2 (Fig. 4), sugerindo que o grau de saturação em $\mathrm{SiO}_{2}$ foi maior nos fluidos formadores do Gs1 e propiciou maior precipitação de quartzo nestas rochas. Assim, como ressaltam Hemley \& Jones (1964), as diferentes zonas mineralógicas - sua distribuição relativa, espessura e conteúdo mineral - refletem a natureza e as atividades relativas dos vários componentes da fase fluida em diferentes pontos dos sítios afetados pelos processos hidrotermais.

As micas dos greisens estudados As micas, pela sua habilidade para trocar componentes com fluidos ou fases sólidas e sua grande sensibilidade às mudanças nas condições de $a H \mathrm{~F}, f \mathrm{H}_{2} \mathrm{O}, f \mathrm{O}_{2} \mathrm{e}$ outras espécies voláteis, são excelentes monitores dos ambientes físico-químicos nos quais se formam (Tischendorf et al. 1997). O acentuado contraste entre os filossilicatos presentes nas associações minerais dos greisens 1 e 2, torna o estudo destes minerais particularmente relevante.

AS MICAS DIOCTAÉDRICAS DO GREISEN 2 Dados experimentais (Monier \& Robert 1986a) indicam que as fengitas do Gs2 devem ter se formado em um ambiente hidrotermal subsolidus de baixa temperatura, pois a extensão da substituição fengítica aumenta com as temperaturas decrescentes e as fengitas do Gs2 apresentam ampla substituição e estão distribuídas bem abaixo da isoterma de $400^{\circ} \mathrm{C}$ (Fig. 8e). Esta estimativa de temperatura é reforçada pela aplicação do geotermômetro de Zang \& Fyfe (1995) para o cálculo de temperaturas de formação da clorita associada ao Gs2 que indica valores entre $320^{\circ} \mathrm{Ce} 265^{\circ} \mathrm{C}$ na ZC, e valores entre $285^{\circ} \mathrm{C}$ e $235^{\circ} \mathrm{C}$ na ZF (Borges 2002). Além disso, estudos das inclusões fluidas presentes no quartzo de ambas as zonas (Borges 2002) também fornecem baixas temperaturas $\left(250^{\circ}\right.$ a $\left.100^{\circ} \mathrm{C}\right)$ para os fluidos envolvidos na formação dessa associação mineral.

Velde (1965) demonstrou, por estudos experimentais, que a fengita tipicamente se forma sob condições de baixa temperatura e alta pressão parcial de $\mathrm{H}_{2} \mathrm{O}$, onde $P_{\mathrm{H} 2 \mathrm{O}}=P_{\text {total }}$. Este autor estudou a estabilidade de assembléias minerais com muscovita e clorita em sedimentos argilosos submetidos a condições metamórficas de grau muito baixo. A baixa temperatura e com um aumento da $P_{\mathrm{H} 2 \mathrm{O}}$ a muscovita da paragênese original enriquece em $\mathrm{Fe}^{2+}$ e origina a fengita, enquanto a clorita em equilíbrio é relativamente mais pobre 

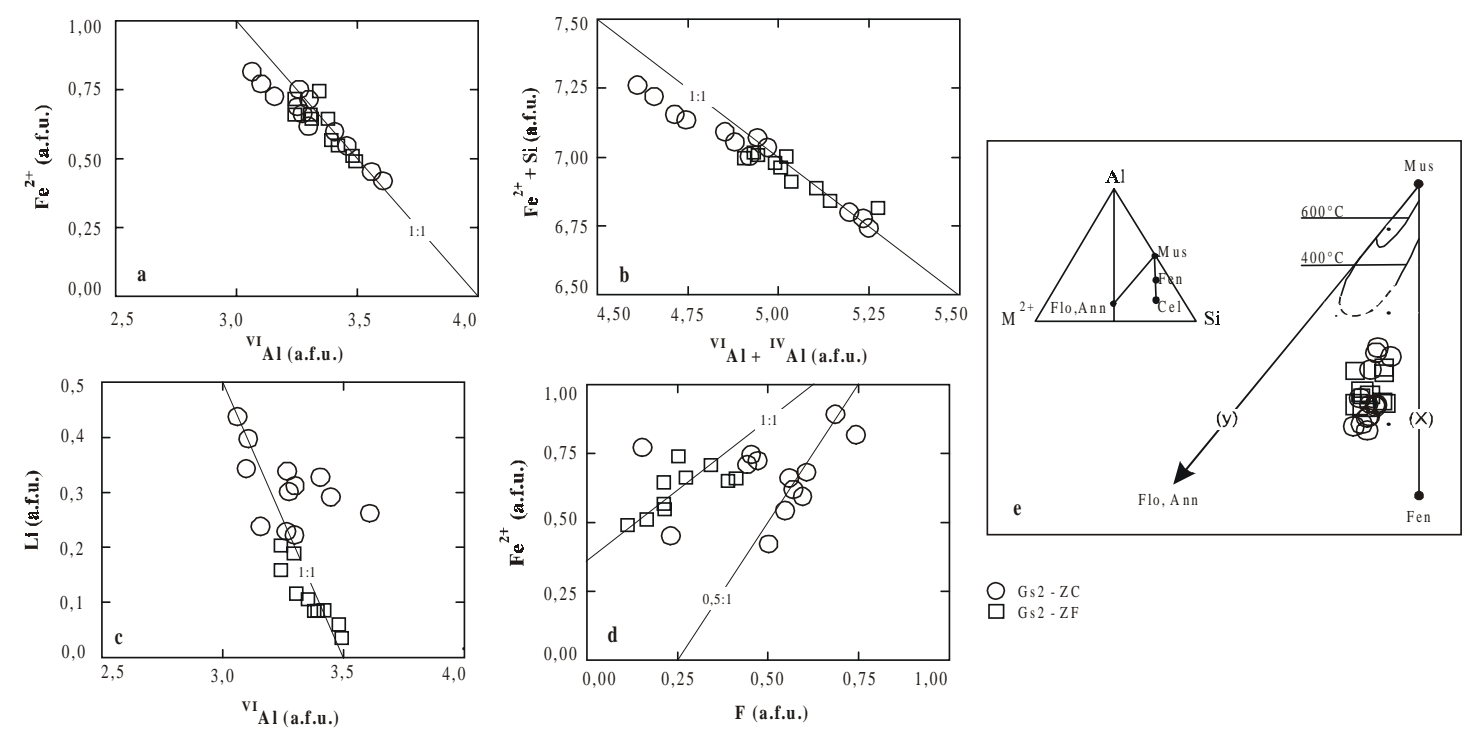

\section{$\bigcirc \mathrm{Gs} 2 \cdot \mathrm{ZC}$
$\square \mathrm{Gs} 2 \cdot \mathrm{ZF}$}

Figura 8 - a) até d) diagramas de correlação de cátions das micas dioctaédricas do Gs2; e) comportamento das micas dioctaédricas no diagrama Al-M+2+Si de Monier \& Robert (1986a). Mus: muscovita; Fen: fengita; Cel: celadonita; Ann: annita; Flo: flogopita; $\mathrm{Al}={ }^{V I} \mathrm{Al}+{ }^{I V} \mathrm{Al} ; \mathrm{M}^{2+}=\mathrm{Fe}^{2+}, \mathrm{Mg}^{2+} ;(x)=$ substituição fengítica; $(y)=$ substituição biotítica; ZC=zona rica em clorita; $Z F=z o n a$ rica em fengita; a.f.u.: átomos por fórmula unitária.

em $\mathrm{R}^{2+}$ e mais aluminosa. No Gs2, a fengita da ZC é mais rica em $\mathrm{Fe}^{2+}$ do que a da ZF, enquanto que a clorita em equilíbrio (Borges 2002) é mais pobre em $\mathrm{Fe}^{2+}$ e mais rica em $\mathrm{Al}^{3+}$ do que a da $\mathrm{ZF}$, o que sugere que a associação do Gs2 da ZF formou-se em temperatura mais elevada que a da $\mathrm{ZC}$, apesar das suas semelhanças.

AS MICAS TRIOCTAÉDRICAS DO GREISEN 1 No Gs1, estudos de inclusões fluidas em quartzo e topázio da ZT e em quartzo da ZS (Borges 2002), revelam que, na ZT, as temperaturas mínimas de aprisionamento de fluidos primários aquo-carbônicos variam entre $380^{\circ} \mathrm{C}$ e $210^{\circ} \mathrm{C}$, enquanto que aquelas dos fluidos aquosos variam entre $310^{\circ} \mathrm{C}$ e $165^{\circ} \mathrm{C}$. A comparação destes dados termométricos com aqueles obtidos na ZF e ZC sugerem que a siderofilita se formou a temperaturas superiores àquelas de formação da fengita e clorita no Gs2.

Na Amazônia, o Gs1 é uma das poucas ocorrências de greisen contendo siderofilita em sua composição mineralógica primária. Dos exemplos conhecidos, é provável que a rocha que mais se aproxima composicionalmente do Gs1 seja o topázio-protolitionitaquartzo-greisen associado ao Maciço Santa Bárbara em Rondônia (Sparrenberger \& Bettencourt 2000), e que a mica descrita como "protolitionita", termo em desuso na literatura, seja uma siderofilita litinífera. Na Província Estanífera do Sul do Pará também foram descritos greisens estaníferos com siderofilita, associados ao Granito Antônio Vicente, da Suíte Intrusiva Velho Guilherme (Teixeira
1999). No entanto, não foram realizadas análises químicas nesta "siderofilita", o que acarreta incertezas sobre sua composição. Em nível de ocorrências mundiais, Bowden \& Kinnaird (1984) descrevem greisens com siderofilita litinífera associados a biotita-granitos mesozóicos dos complexos anelares anorogênicos da Nigéria.

Apesar das diferenças entre seus protólitos, hornblenda-biotitagranito no caso do Gs1, e biotita-granito no caso da Província Nigeriana, constata-se que ambas ocorrências estão nitidamente associadas a granitos tipo-A, da série rapaquivi no caso dos granitos da Amazônia. Desta maneira, o Gs1 apresenta características mineralógicas que o diferenciam da maior parte dos greisens descritos na literatura mundial, associados a granitos do tipo-S, peraluminosos, cujo principal filossilicato é a muscovita.

Agradecimentos Este trabalho é parte da Tese de Doutorado do primeiro autor, que agradece ao CNPq pela concessão de bolsa de estudos (Processo 141.869/1998-4). Ao Grupo Paranapanema S/A pela liberação dos testemunhos de sondagem e apoio logístico nas etapas de campo, ao CNPq (Auxílios 463/96/2000-7; 400038/ 99;550739/01-7) e UFPA (Projetos PROINT CG-212/2000; CG-128/ 2001). Ao Laboratório de Microssonda Eletrônica da UnB pelas análises químicas, ao Prof. Nilson Botelho (UnB) por discussões e revisão do texto e aos revisores da RBG pelas sugestões ao manuscrito. Este trabalho é uma contribuição aos projetos IGCP426(IUGS-UNESCO) ePRONEX-MCT-CNPq (66.2103/1998-0).

\section{Referências}

Borges R.M.K. 1997. Petrografia e química mineral dos greisens associados ao Granito Água Boa - mina Pitinga (AM): um estudo dos processos de formação de greisens. Centro de Geociências, Universidade Federal do Pará, Belém, Dissertação de Mestrado, 190 p.

Borges R.M.K. 2002. Greisens e epi-sienitos potássicos associados ao
Granito Água Boa, Pitinga (AM): um estudo dos processos hidrotermais geradores de mineralizações estaníferas. Centro de Geociências, Universidade Federal do Pará, Tese de Doutorado, 383 p.

Bowden P. \& Kinnaird J.A. 1984. Geology and mineralization of the Nigerian anorogenic ring complexes. Geol. Jahrb., B56:3-65. 
Cerný P. \& Burt D.M. 1984. Paragenesis, crystalochemical characteristics and geochemical evolution of micas in granite pegmatites. In: S.W. Bailey (ed.). Micas - Reviews in Mineralogy. New York. Mineralogical Society of America. 257-298.

Charoy B., Chaussidon M., Noronha F. 1995. Lithium zonation in white micas from the Argemela microgranite (central Portugal): an in-situ ion-electron-microprobe and spectroscopic investigation. Eur. J. Mineral.,7:335-352.

Costi H.T. 2000. Petrologia de granitos alcalinos com alto flúor mineralizados em metais raros: o exemplo do albita-granito da Mina Pitinga, Amazonas, Brasil. Centro de Geociências. Universidade Federal do Pará, Belém. Tese de Doutorado, 345 p.

Costi H.T., Dall'Agnol R., Moura C.A.V. 2000a. Geology and Pb-Pb geochronology of Paleoproterozoic volcanic and granitic rocks of Pitinga Province, Amazonian Craton, Northern Brazil. Intern. Geol. Rev. 42:832-849.

Costi H.T., Horbe A.M.C., Borges R.M.K., Dall'Agnol R., Rossi A., Sighnolfi G. 2000b. Mineral chemistry of cassiterites from Pitinga Province, Amazonian Craton, Brazil. Rev. Bras. Geoc. 30:775-782.

Costi H.T., Dall'Agnol R., Borges R.M.K., Minuzzi O.R.R., Teixeira J.T. 2002. Tin-bearing sodic episyenites associated with the Proterozoic, A-Type Água Boa Granite, Pitinga Mine, Amazonian Craton, Brazil. Gond. Res., 5:435-451.

Dall'Agnol R., Teixeira N.P., Magalhães M.S. 1993. Diagnostic Features of the tin-specialized granites of the Eastern Amazonian Region. An. Acad. bras. Ci. 65:33-50.

Dall'Agnol R., Lafon J.M., Macambira M.J.B. 1994. Proterozoic anorogenic magmatism in the Central Amazonian Province, Amazonian craton: geochronological, petrological and geochemical aspects. Mineral. Petrol. 50:113-138.

Dall'Agnol R., Bettencourt J.S., Botelho N.F., Klein E.L. 2000. Tin, gold and granitoids in Brazil. In: SBG, International Geological Congress, $31^{\text {st }}$, Rio de Janeiro, Extended Abstracts. CD-ROM.

Daoud W.El K. 1988. Granitos Estaníferos de Pitinga, Amazonas: contexto geológico e depósitos minerais associados. Departamento de Geociências, Universidade de Brasília, Brasília, Dissertação de Mestrado, 194 p.

Daoud W.El K. \& Antonietto Jr. A. 1985. Geologia do Granito Água Boa, Pitinga (AM). In: SBG, Simp. Geol. Amazônia, 2, Belém. Anais. 3:17-33.

Dymek R.F. 1983. Titanium, aluminium and interlayer cation substitutions in biotite from high-grade gneisses, West Greenland. Amer. Mineral., 68:880-889.

Foster M.D. 1960a. Layer charge relations in the dioctahedral and trioctahedral micas. Am. Mineral., 45:383-398.

Foster M.D. 1960b. Interpretation of the composition of lithium micas. Washington, Geol. Surv. Prof. Paper, 36 p. (354-E).

Frank R.E. \& Pires F.R. 1991. Mineralizações estaníferas do Complexo Granítico Santa Bárbara, Rondônia. In: Simp. Geol. Amazônia, 3, Belém. Anais: 307-321.

Guidotti C.V. 1984. Micas in metamorphic rocks. In: S.W. Bailey (ed.) Micas. Reviews in Mineralogy. New York. Mineralogical Society of America. 357-467.

Hemley J.J. \& Jones W.R. 1964. Chemical aspects of hydrothermal alteration with emphasis on hydrogen metasomatism. Econ. Geol., 59:538-569.

Horbe M.A., Horbe A.C., Costi H.T., Teixeira J.T. 1991. Geochemical characteristics of cryolite-tin-bearing granites from Pitinga Mine, northwestern Brazil - a review. Jour. Geochem. Explor., 40:227-249.

Kühne R., Wasternack J., Schulze H. 1972. Post-magmatische Metasomatose im Endo-Exokontakt der jüngeren postkinematischen Granite des Erzgebirges. Geologie. 21(4/5):494-520.

Lenharo S.L.R. 1998. Evolução magmática e modelo metalogenético dos granitos mineralizados da região de Pitinga, Amazonas, Brasil. São Paulo, Escola Técnica da Universidade de São Paulo, USP, São Paulo. Tese de Doutorado. 290 p.

Monier G. \& Robert J. 1986a. Muscovite solid solutions in the system $\mathrm{K}_{2} \mathrm{O}-\mathrm{MgO}-\mathrm{FeO}-\mathrm{Al}_{2} \mathrm{O}_{3}-\mathrm{SiO}_{2}-\mathrm{H}_{2} \mathrm{O}$ : an experimental study at $2 \mathrm{Kbar}$ $\mathrm{P}_{\mathrm{H} 2}$ and comparison with natural Li-free white micas. Mineral. Mag., 50:257-266.

Monier G. \& Robert J. 1986b. Evolution of the miscibility gap between muscovite and biotite solid solutions with increasing lithium content: an experimental study in the system $\mathrm{K}_{2} \mathrm{O}-\mathrm{Li}_{2} \mathrm{O}-\mathrm{MgO}-\mathrm{FeO}-\mathrm{Al}_{2} \mathrm{O}_{3}$ $\mathrm{SiO}_{2}-\mathrm{H}_{2} \mathrm{O}-\mathrm{HF}$ at $600^{\circ} \mathrm{C}, 2 \mathrm{Kbar} \mathrm{P}_{\mathrm{H}_{2}}$ : comparison with natural lithium micas. Mineral. Mag., 50:641-651.

Moura M.A. \& Botelho N.F. 1994. Estudo de micas litiníferas e sua importância para a caracterização das rochas da Zona Greizenizada Principal do maciço estanífero Mangabeira, GO. Bol. de Geoc. do Centro-oeste, 17(1/2):39-48.

Sparrenberger I. \& Bettencourt J.S. 2000. The tin mineralization at the Santa Bárbara Massif, Rondônia Tin Province, Brazil. In: SBG, International Geological Congress, $31^{\text {st }}$, Rio de Janeiro, Extended Abstracts. CD-ROM.

Sun S. \& Yu J. 1999. Fe-Li micas: a new approach to the substitution series. Mineral. Mag. 63:933-945.

Teixeira N.P. 1999. Contribuição ao estudo das rochas granitóides e mineralizações associadas da Suite Intrusiva Velho Guilherme, Província Estanífera do Sul do Pará. Instituto de Geociências. Universidade de São Paulo. USP. Vol. 1 e 2, Tese de Doutoramento. 508 p.

Tindle A.G. \& Webb P.C. 1990. Estimation of lithium contents in trioctahedral micas using microprobe data: application to micas from granitic rocks. Eur. J. Mineral., 2:595-610.

Tischendorf G., Gottesmann B., Förster H.J., Trumbull R.B. 1997. On Li-bearing micas: estimating $\mathrm{Li}$ from electron microprobe analyses and an improved diagram for graphical representation. Mineral. Mag., 61:809-834.

Velde B. 1965. Phengite micas: synthesis, stability, and natural occurrence. Am. J. Sci., 263:886-913.

Yokoi O.Y., Viglio E.P., Waghorn J.G., Jones J.P., Figueroa L.A. 1987. Potosi, a primary tin deposit in Rondônia. Rev. Bras. Geoc., 17:557-561.

Zang W. \& Fyfe W.S. 1995. Chloritization of the hidrothermally altered bedrock at the Igarapé Bahia gold deposit, Carajás, Brazil. Mineral. Depos., 30:30-38.

Manuscrito A-1320

Recebido em 22 de janeiro de 2002

Revisão dos autores em 30 de março de 2003

Revisão aceita em 5 de abril de 2003 